ISSN: 0514-7336

DOI: http://dx.doi.org/10.14201/zephyrus2015754171

\title{
RELEYENDO EL FENÓMENO DE LA NEOLITIZACIÓN EN EL BAJO ARAGÓN A LA LUZ DE LA EXCAVACIÓN DEL CINGLE DE VALMAYOR XI (MEQUINENZA, ZARAGOZA)
}

\section{Reviewing the Neolithisation phenomenon in the Lower Aragón region in the light of the excavation in the rock shelter of Valmayor XI (Mequinenza, Zaragoza)}

Manuel A. Rojo Guerra*, Cristina Tejedor Rodríguez**, Leonor Peña Chocarro***, J. Ignacio Royo Guillén ${ }^{* * * *}$, Ínigo García Martínez de Lagrán*****, Héctor Arcusa Magallón******, María San Millán Lomas*******, Rafael Garrido Pena********, Juan F. Gibaja Bao*******, Niccolò Mazzuco*******, Ignacio Clemente Conte*******, Millán Mozota Holgueras ${ }^{* * * * * * *}$, Xavi Terradas Batlle******, Mar-

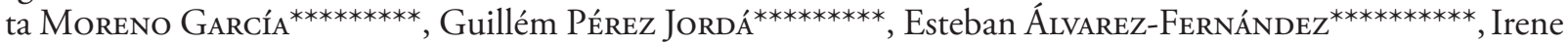
JimÉneZ JimÉneZ ${ }^{* *}$ y Fabiola Gómez LeCUMBERRI ${ }^{* * * * * * * * * * *}$

* Dpto. de Prehistoria y Arqueología. Facultad de Filosofía y Letras. Plaza del Campus, s/n. 47011 Valladolid (España).Correo-e: marojo@fyl.uva.es

** Instituto Arcadia. Fundación General Univ. Valladolid. Residencia Universitaria Alfonso VIII. C/ Real de Burgos,s/n.47011Valladolid.Correo-e: tejedor.cristina@gmail.com; irene.jimenezjim@gmail.com

*** Escuela Española de Historia y Arqueología en Roma-CSIC. Via di Torre Argentina, 18. 00186 Roma. Correo-e: leonor.chocarro@csic.it

**** Dirección General de Patrimonio Cultural. Gobierno de Aragón. Avda. Gómez Laguna, 25, 6. planta. 50009Zaragoza.Correo-e: jiroyo@aragon.es

***** Dpto. de Prehistoria. Facultad de Filosofía y Letras UPV-EHU. C/ Francisco Tomás y Valiente, s/n. 01006 Vitoria.Correo-e: igmtzl@gmail.com

****** Técnico Arqueólogo. Cl Zaragoza, 9-11-13, esc. 3, 2. C. 50196 La Muela (Zaragoza). Correo-e: hectorarcusa@gmail.com

******* Instituto Milà i Fontanals. Dpto. de Arqueología y Antropología. Dinámicas de Arqueología Social (IMFCSIC).C/ Egipciaques, 15.08001 Barcelona.Correo-e: maria.lomas29@gmail.com; jfgibaja@imf.csic.es; niccomazzucco@imf.csic.es; ignacio@imf.csic.es; millanm@imf.csic; terradas@imf.csic.es

******** Dpto. de Prehistoria y Arqueología. Facultad de Filosofía y Letras-UAM. Carretera de Colmenar Viejo, km 15. 28049 Cantoblanco (Madrid). Correo-e: rafael.garrido@uam.es.

********* Instituto de Historia, CCHS-CSIC. Cl Albasanz, 26-28. 28037 Madrid. Correo-e: marta.moreno@cchs. csic.es; guillem.perez@uv.es

********* Dpto. de Prehistoria, H. a Antigua y Arqueología. Facultad de Geografía e Historia. Cl Cervantes, s/n. 37002 Salamanca. Correo-e: epanik@usal.es

*********** Técnico Arqueólogo. Cl Lucas Gallego, 58, 3. izqda. 50009 Zaragoza. Correo-e: fabiolaglecum@ gmail.com

Recepción: 28/01/2015; Revisión: 6/02/2015; Aceptación: 25/03/2015

BIBLID [0514-7336 (2015) LXXV, enero-junio; 41-71]

(c) Universidad de Salamanca

Zephyrus, LXXV, enero-junio 2015, 41-71 
Resumen: Este trabajo presenta los resultados preliminares obtenidos en la excavación del Cingle de Valmayor XI, desarrollada dentro del proyecto de investigación 'Los caminos del Neolítico'. A través del análisis de las dataciones radiocarbónicas y de una detallada lectura estratigráfica se han podido establecer tres horizontes de ocupación diferentes con cronologías que corresponden a distintos momentos del vi milenio cal BC. Se ofrece una descripción general de los eventos arqueológicos documentados en cada una de estas fases, así como de gran parte del material recuperado -cerámica, lítica, industria ósea, elementos de adorno, fauna y restos carpológicos-. Por otra parte, a la luz de las nuevas dataciones presentadas, se propone una revisión del fenómeno de la neolitización en la región del Bajo Aragón y, por extensión, en todo el valle del Ebro; también se cuestiona la identificación de contextos como propios de economías productoras simplemente a través de la presencia de ciertos elementos materiales considerados tradicionalmente como 'marcadores neolíticos', sin que existan variaciones con respecto a las estrategias subsistenciales o de explotación del territorio.

Palabras clave: Mesolítico; Neolítico antiguo; dataciones radiocarbónicas; cerámica neolítica; tecnología lítica.

АвSTRACT: This paper presents the preliminary results of the excavation of the Valmayor xI rock shelter, in the context of the research project 'The pathways of the Neolithic'. Through the analysis of the radiocarbon dates and a detailed stratigraphic interpretation three occupations have been established with chronologies within different periods of the vith millennium cal BC. A general description of the archaeological events documented in each phase, and of most of the recovered material -pottery, lithic artefacts, bone industry and ornaments, faunal and carpological remains- is offered. Moreover, in the light of the new dates presented, a review of the Neolithisation process in the Lower Aragón region, and also in the Ebro valley, is proposed. Also the identification of archaeological sites as Neolithic ones only on the basis of the presence of some elements considered as 'Neolithic markers', without any consideration of the subsistence strategies or territorial exploitation, is questioned.

Key words: Mesolithic; Early Neolithic; radiocarbon dates; Neolithic pottery; lithic technology.

\section{El Cingle de Valmayor XI: un enclave estratégico en pleno valle del Ebro ${ }^{1}$}

Fue descubierto por los miembros del Grupo de Investigación 'Coses del Poble' de la localidad de Mequinenza, Francisco Copons y José Carbonell, durante la sequía del año 2005. Se localiza en el confín oriental del término municipal, a unos $18 \mathrm{~km}$ de la población, y ocupa un extenso

1 La línea de investigación principal de este trabajo se desarrolla en el marco de los proyectos "Los Caminos del Neolítico" (Har2009-09027) y "Los Caminos del Neolítico II" (HAR2013-46800-P) bajo la dirección de M. Rojo Guerra, concedidos por la Subdirección General de Proyectos de Investigación/Dirección General de Investigación y Gestión del Plan Nacional de I + D+ I/Secretaría de Estado de Investigación, del Ministerio de Ciencia e Innovación, y cofinanciado por el Gobierno de Aragón. La parte analítica y las dataciones radiocarbónicas se han realizado dentro del proyecto "Origins and spread of agriculture in the western Mediterranean region” (ERC-2008-AdG 230561), coordinado por L. Peńa Chocarro y financiado por el European Research Council. cingle o afloramiento de areniscas a media ladera del barranco que da nombre al yacimiento (Fig. 2a). Se trata de un área de captación de aguas procedentes de una extensa superficie que acaba por drenar en la orilla derecha del Ebro. En la actualidad el yacimiento se encuentra totalmente cubierto por el embalse de Mequinenza, salvo en los periodos de estiaje, que suelen coincidir con el final del verano e inicios del otoño.

Este abrigo se ubica a $120 \mathrm{msnm}$, en un potente afloramiento de arenisca oligocena orientado al S-SE -coordenadas UTM Huso 30: x-260.450/ y-4.578.850-. Su cornisa, de una anchura mayor de $4 \mathrm{~m}$, conforma una cavidad muy alargada con una boca de más de $50 \mathrm{~m}$, una profundidad que oscila entre los 3-4 m y una altura media desde el techo al nivel superficial de poco más de $2 \mathrm{~m}$.

En relación al emplazamiento, cabría destacar dos aspectos muy interesantes: por una parte, su ubicación estratégica en medio de varias vías de tránsito naturales y, por otra, su localización en una zona muy apta para el asentamiento humano 


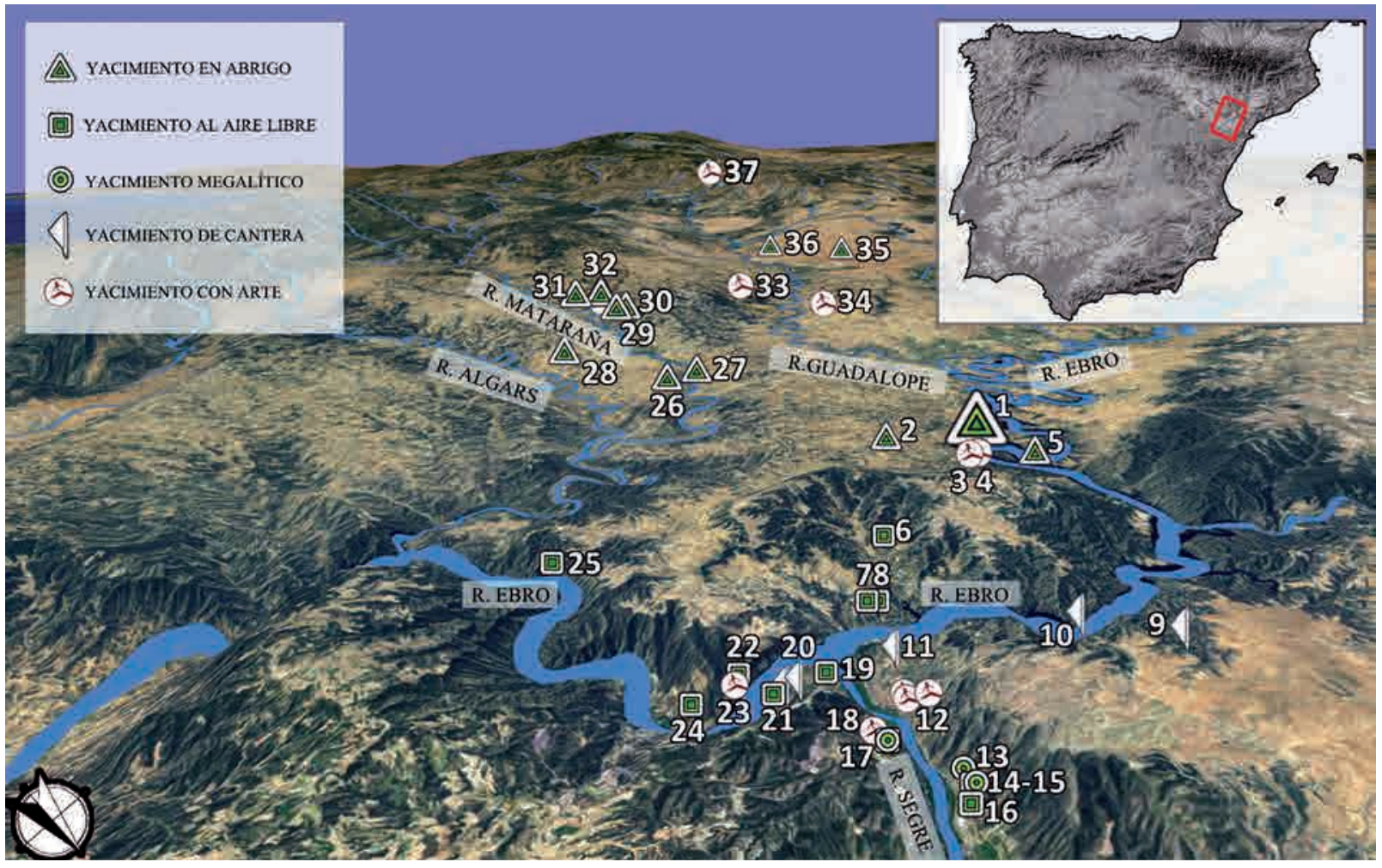

FIG. 1. Localización del Cingle de Valmayor XI y de los yacimientos coetáneos en el Bajo Aragón, en relación con algunos 'yacimientos de cantera': 1) Valmayor XI; 2) Mas de Orleans; 3) Valmayor XIV; 4) Valmayor XII y XIII; 5) Roca del Ciervo; 6) Creveta; 7) Mina Villarroya; 8) Sierra de la Huerta I; 9) Valporquera; 10) Sierra de los Rincones II; 11) La Plana I; 12) Vallbufandes III, IV y V; 13-16) Riols IV, II, III y I; 17) Barranco de Mina Vallfera; 18) Barranco de Campells III; 19) De la Segre Alta II; 20-21) Barranco de Alcañiz I y III; 21) Barranco de Alcañiz II; 22-23) Valdirrera Iy II; 24) Aubera I; 25) Vall de Granada; 26) El Serdá; 27) Sol de la Piñera; 28) Costalena; 29) El Pontet; 30) Cueva Ahumada; 31) Cueva del Llop; 32) Botiquería dels Moros y Els Secans; 33) Val del Charco del Agua Amarga; 34) El Plano del Pulido; 35) Las Torrazas; 36) Alonso Norte; 37) Abrigos del Ángel I y II.

en la Prehistoria reciente, como indican los numerosos hallazgos arqueológicos documentados en el entorno (Fig. 1).

\subsection{Ubicación en zona de paso}

El yacimiento se encuentra en un corredor natural entre los ríos Ebro y Matarraña, en un entorno especialmente singular perteneciente al término municipal de Mequinenza, a caballo entre las tierras del Bajo Aragón y las del Bajo Cinca y Segre, y junto al extremo se de la comarca aragonesa de Los Monegros (Fig. 1). Este emplazamiento geoestratégico, a menos de $100 \mathrm{~km}$ de las costas mediterráneas, debió constituir un punto crucial de las comunicaciones naturales durante la Prehistoria reciente, hecho que se refleja en su riqueza arqueológica (Royo y Gómez, 1996: 769-770 y 2004: 67-72).

Las especiales condiciones orográficas del entorno, con extensas planicies y profundos valles excavados en los sedimentos de calizas y areniscas, determinan la complicada comunicación entre unas zonas y otras, de modo que los ríos han asumido un papel especialmente importante en este aspecto. El Segre y su cercano afluente el Cinca, el Matarraña y, como principal eje vertebrador de este sistema hídrico, el río Ebro, junto a sus barrancos subsidiarios, han servido de auténticos corredores naturales, permitiendo el paso entre los encajados valles de este territorio a lo largo de la Historia. 


\subsection{Entorno apto para el asentamiento humano en la Prehistoria reciente}

Toda el área descrita es muy rica en hallazgos arqueológicos. Su relevancia en época prehistórica queda fuera de toda duda a tenor de la existencia de numerosos abrigos con arte rupestre esquemático, tanto pintado como grabado (Royo, 1986-1987) (Fig. 1). Los trabajos de prospección y excavación llevados a cabo en este territorio durante más de 14 años (Royo y Gómez, 1991, 1996 y 2004) han dado lugar a un importante catálogo de yacimientos, con una gran variedad de estructuras y restos materiales documentados (Fig. 1). Con anterioridad a la intervención de la que es objeto este artículo, destacan las actuaciones desarrolladas en los enclaves del Barranco de la Mina Vallfera (Royo, 1984 y 1987; Royo y Gómez, 1996: 768, 772-773) y Riols I (Royo y Gómez, 1992 y 1997). Las dataciones disponibles para este último yacimiento corresponden en su totalidad a cronologías neolíticas (Gómez et al., 1992: 49-51), destacando en esta ocasión las de los niveles más antiguos $-6040 \pm$ 100 вр, 5216-4720 cal вс- por su posible correspondencia con uno de los momentos de ocupación del Cingle de Valmayor XI - Valmayor XI-III(cf. apartado 2).

Varios factores pudieron favorecer la temprana ocupación de este territorio. Así, la proximidad de recursos hídricos, la existencia de buenas tierras para el cultivo o el amplio control visual del entorno son variables sin duda determinantes a la hora de asentarse en un territorio (Fig. 1). Además, se ha constatado la proximidad geográfica de algunos de los enclaves antrópicos a áreas de abastecimiento de diversas materias primas, principalmente de naturaleza lítica (Royo y Gómez, 1996: 772 y 2004: 71).

\section{Lectura estratigráfica y cronológica de la secuencia de Valmayor XI}

El Cingle de Valmayor xi ha sido objeto de una única campaña de excavación en 2011, en la cual se intervino en un espacio de unos $26 \mathrm{~m}^{2}$ aproximadamente, dividido en dos áreas diferenciadas por una franja de $50 \mathrm{~cm}$ (Fig. 2a y b). En la parte más oriental, de unos $14 \mathrm{~m}^{2}$, no llegó a excavarse la estratigrafía completa en su totalidad, sino que en ciertas zonas de la misma sólo fue posible registrar los primeros niveles de ocupación -fundamentalmente en la zona más cercana a la pared del abrigo, donde existe una mayor potencia sedimentaria-. Se identificaron un total de 52 unidades conformando un paquete estratigráfico que apenas llega a alcanzar los $50 \mathrm{~cm}$ de espesor - sin tener en cuenta los niveles no antrópicos, UUEe 14 y 19-(Figs. 2c y 3a). El derrumbe de grandes bloques pétreos procedentes del techo y pared del abrigo en época prehistórica, en concreto en un momento de vacío poblacional del asentamiento entre las fases identificadas como Valmayor XI-II y III, ha permitido preservar en cierta medida su estratigrafía, principalmente en los sectores localizados hacia el interior del cingle. Sin embargo, las capas superficiales no cubiertas por estos eventos de derrumbe se encuentran alteradas notablemente por la acción del flujo y reflujo de las aguas del pantano. Los fenómenos postdeposicionales sufridos por este yacimiento, así como su formación sedimentológica, son procesos muy significativos y de tal complejidad que serán objeto en un futuro de una publicación específica. Su estudio, actualmente en elaboración, revela que, si bien todos los niveles de ocupación han sido alterados por diversos procesos tafonómicos, no lo han sido en la misma medida como demuestra el hallazgo de numerosas estructuras in situ (Fig. 3b-f), fundamentalmente en las zonas protegidas bajo la visera del cingle. Por tanto, la disposición de las diferentes capas sedimentarias dentro del propio yacimiento es uno de los factores que más ha determinado su estado de conservación.

El análisis de la secuencia estratigráfica junto con las dataciones disponibles nos han llevado a identificar tres momentos de ocupación (Fig. 4), que abarcan un importante lapso cronológico hasta finales del vi milenio cal вС:

- Valmayor XI-I: es la fase más antigua del yacimiento y la única que no ha podido ser datada, debido a la ausencia de eventos singulares de vida corta adecuados para tal cometido. Este nivel se conforma por la sucesión de dos horizontes antrópicos diferentes, con un marcado buzamiento siguiendo la pendiente de la ladera. Ambos se corresponden con los primeros eventos de actividad humana detectados, apoyándose el más antiguo -UE 21- directamente sobre un estrato estéril -UE 14- resultante 

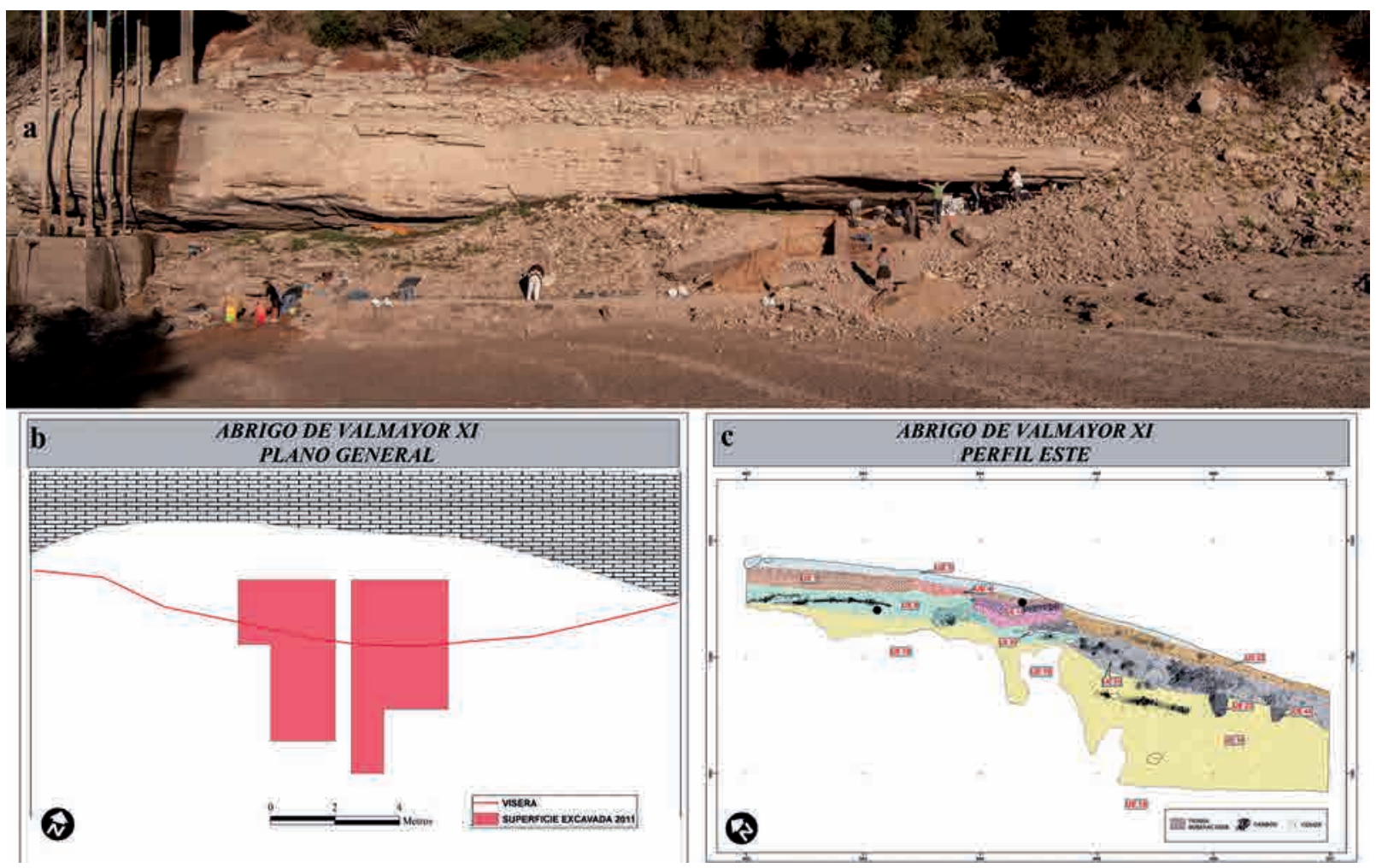

FIG. 2. Cingle de Valmayor XI: (a) imagen general, b) plano de las áreas de excavación y c) perfil E de la intervención.

de la erosión de la roca madre -ue 19- (Figs. 2c y 3a). Su excavación se ha restringido únicamente a un pequeño sector localizado hacia el exterior de la visera del abrigo -aproximadamente $4 \mathrm{~m}^{2}$-, en el que se han documentado dos hoyos de poste $y$ escaso material arqueológico -fundamentalmente industria lítica, algunos restos de fauna y ausencia total de cerámica-. Todas las evidencias apuntan hacia una cronología mesolítica para este momento de ocupación.

- Valmayor XI-II: este nivel de ocupación (Fig. 4), que se ha localizado en la mitad superior del área excavada extendiéndose un poco hacia la ladera, tiene una cronología de mediados del vi milenio cal BC $-6750 \pm 30$ BP-. Se caracteriza por la abundante presencia de carbones y huellas de fuego, definidas por manchas de tierra rubefactada de diferentes tamaños. En el sector interno del abrigo, este horizonte se asienta sobre las capas de sustrato natural, mientras que hacia el exterior cubre parcialmente las unidades sedimentarias que conforman el momento de ocupación anterior (Figs. 2c y 3a). Apoyado directamente sobre este nivel, cubriéndolo y preservándolo en cierta medida, se documentó un importante derrumbe -UE 25- de grandes lajas de arenisca desprendidas del techo del cingle (Fig. 3a); este evento, que se registró sobre todo en la parte más oriental de la intervención, habría tenido lugar concretamente en un lapso cronológico entre esta fase ocupacional y la posterior. En este horizonte se ha recuperado abundante material arqueológico, principalmente industria lítica, algunos restos de fauna y cerámica -en ocasiones decorada-, además de varias cuentas de collar y otros elementos de adornos. Por otra parte, se han documentado numerosos hogares de morfología más o menos homogénea, consistentes en una cubeta excavada de forma circular o ligeramente ovalada y con un $1 \mathrm{~m}$ de diámetro aproximadamente -se han identificado algunos de menor tamaño-; suelen aparecer delimitados por un círculo de tierra 

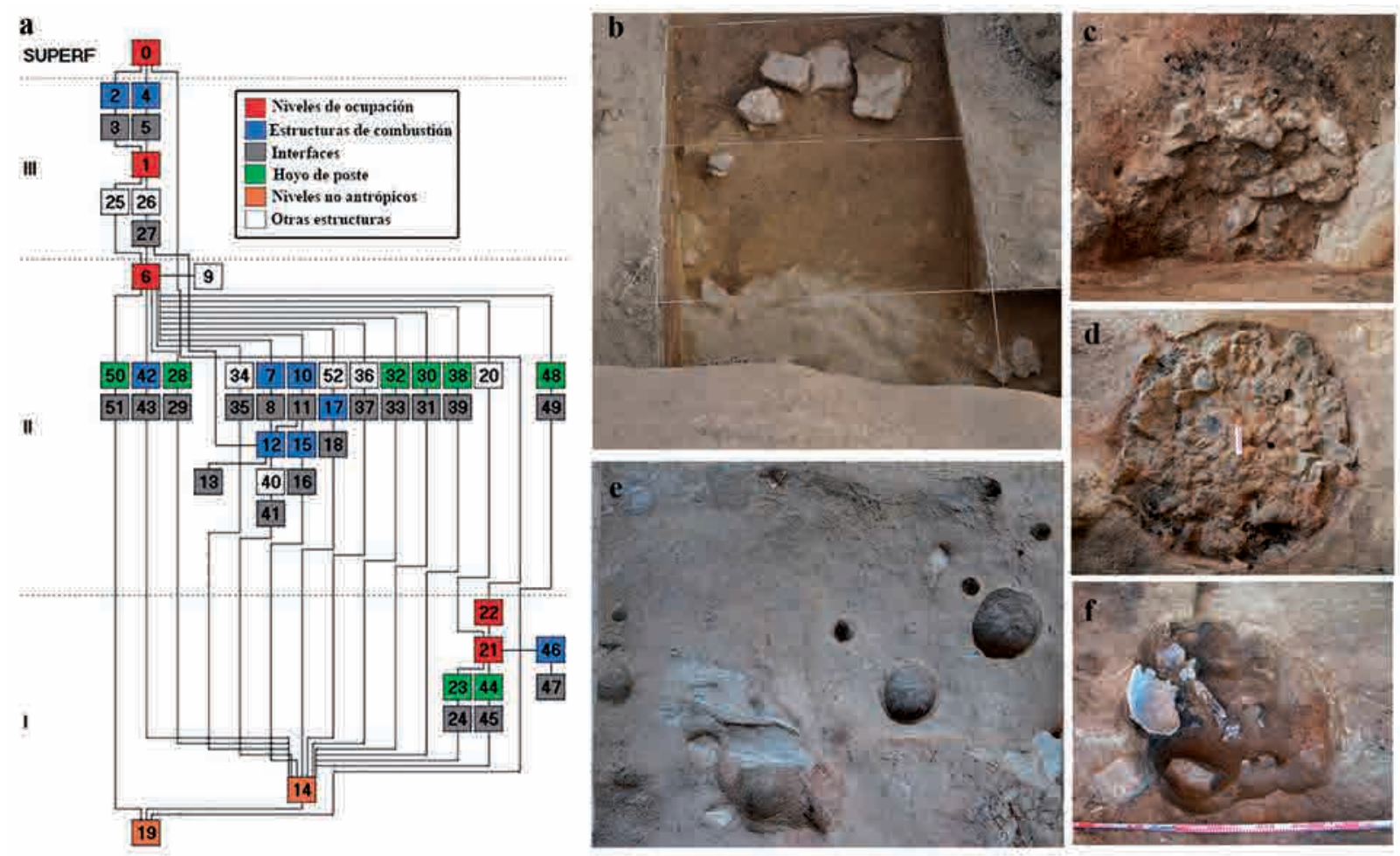

FIG. 3. Cingle de Valmayor XI: a) secuencia estratigráfica y b-f) algunas de las estructuras citadas en el texto.

rubefactada y amortizados por un relleno de piedras de pequeño tamaño, en cuyo interior se han registrado escasos materiales arqueológicos (Fig. 3a, c y d). Una de estas estructuras de combustión presenta unas características diferentes -UE 12-, puesto que consiste en una gran mancha de tierra rubefactada cuyas dimensiones superan los $2 \mathrm{~m}^{2}$ y con una potencia mayor de $10 \mathrm{~cm}$, que parece ser el resultado de la acción potente y continuada del fuego en un mismo lugar. En ella, se han recuperado numerosos restos de talla minúsculos junto con cenizas y carbones, evidencias que han llevado a plantear la posibilidad de que se trate de un área destinada al trabajo de la talla de sílex. También se ha identificado en este horizonte de ocupación un alineamiento semicircular de varios hoyos de poste equidistantes entre sí, asociados a tres cubetas de escasa profundidad, que podrían corresponder a una estructura realizada con postes de madera para delimitar un espacio en el sector más interno del cingle (Fig. 3a y e). Por último, se ha identificado un pequeño alineamiento de piedras -UE 20- que podría haber formado parte de una estructura de cerramiento (Figs. 2c y 3b).

- Valmayor XI-III: localizada hacia el interior de la visera (Fig. 4), esta fase se corresponde con el último momento de ocupación prehistórica del lugar, fechado a finales del vi milenio cal BC -6090 $\pm 30 \mathrm{BP}-$. Contiene igualmente un único nivel antrópico, apoyado directamente sobre el anterior horizonte ocupacional, y en algunos sectores sobre un evento de derrumbe -ue 25- (Figs. 2c y 3 a) que ha permitido su buena conservación en las partes más altas del abrigo. Por el contrario, hacia el exterior de la visera del abrigo este nivel ha desaparecido por el arrastre del agua. Se caracteriza por las numerosas inclusiones de carbones de pequeño tamaño y la presencia de abundante industria lítica y del mayor porcentaje de la cerámica recuperada en este yacimiento. Además, se han identificado algunas estructuras de combustión y un hoyo de gran tamaño -UE 26- que fue completamente colmatado por piedras, y en cuyo interior se hallaron numerosos materiales 


\begin{tabular}{|c|c|c|c|c|c|c|}
\hline $\begin{array}{c}\text { FASE DE } \\
\text { OCUPACIÓN }\end{array}$ & $\begin{array}{c}\text { N. } .^{\circ} \text { DE } \\
\text { LABORATORIO }\end{array}$ & CONTEXTO & $\begin{array}{c}\text { TIPO } \\
\text { MUESTRA }\end{array}$ & DATACIÓN BP & $\begin{array}{c}\text { CAL. BC 1 } \sigma \\
\text { OxCal v.4.2.3 }\end{array}$ & $\begin{array}{c}\text { CAL. BC } 1 \sigma \\
\text { OxCal v.4.2.3 }\end{array}$ \\
\hline VALMAYOR II & Beta -341168 & UE 6 & Fauna & $6570 \pm 30$ & $\begin{array}{c}5537 / 5485 \\
(68.2 \%)\end{array}$ & $\begin{array}{c}5563 / 5478(89.3 \%) \\
5609 / 5593(6.1 \%)\end{array}$ \\
\hline VALMAYOR III & Beta -341167 & UE 1 & Fauna & $6090 \pm 30$ & $\begin{array}{c}5045 / 4959 \\
(68.2 \%)\end{array}$ & $\begin{array}{c}5075 / 4909(89.7 \%) \\
5304 / 5170(5.7 \%)\end{array}$ \\
\hline
\end{tabular}

FIG. 4. Tabla de dataciones de Valmayor XI sobre muestras de vida corta (fauna).

arqueológicos (Fig. 3a y f) de gran calidad -cuentas de collar y colgantes, importantes piezas líticas o el único recipiente cerámico casi completo hallado in situ de todo el yacimiento-.

Por último, se ha documentado un nivel superficial -uE 0 - producto de la erosión del yacimiento (Fig. 2c), en el que se ha recuperado una gran cantidad de material arqueológico como cerámicas -lisas y decoradas-, restos faunísticos, elementos de adorno, pulimentos y fundamentalmente industria lítica. Junto a estos materiales han aparecido algunos elementos de época reciente, pero en ningún caso evidencias de ocupaciones prehistóricas posteriores a las referidas en este epígrafe.

Teniendo en cuenta todos los factores expuestos, quedan patentes tres cuestiones dignas de señalar en relación con la secuencia de Valmayor XI:

- La existencia de una fase propiamente mesolítica previa al 5609-5478 cal BC -Valmayor XII- que, a falta de una mayor precisión debido a la ausencia de dataciones absolutas, vendría a cubrir, en cierta medida, el vacío poblacional que algunos investigadores plantean para el Bajo Aragón entre el 6200 y el 5700 cal вс (Utrilla et al., 2009: 171), у que se correspondería con la tradicionalmente denominada 'fase в del Mesolítico de triángulos'.

- La necesidad de fijar la llamada 'fase c o de transición al Neolítico' (ibídem: 177) en torno a mediados del vi milenio cal $\mathrm{BC}$, coincidiendo con las dataciones de Botiquería dels Moros 4 y asimilando a este momento contextos como los de Pontet Cinf, Costalena c3 y Secans irb. Los datos obtenidos en Valmayor XI estarían cuestionando, por tanto, la hipótesis defendida para el Bajo Aragón de la existencia de un periodo de abandono generalizado o 'fase B', seguido de una reocupación de los yacimientos tras un amplio periodo de vacío poblacional. Dentro de este marco interpretativo, en nuestra opinión el horizonte de Valmayor XI-II podría definirse como un 'contexto mesolítico con elementos neolíticos' (cf. apartado 4.2).

- El desarrollo de contactos entre las poblaciones mesolíticas asentadas en el Bajo Aragón y los 'pioneros neolíticos' que darían lugar, en torno al 5300-5000 cal BC, a un fenómeno de plena neolitización de todos los grupos tanto en sus bases subsistenciales como económicas y sociales -Valmayor XI-III-. El mecanismo de este proceso, cuestión sobre la que se incidirá a lo largo de este artículo ( $c f$. apartado 4), debe ser objeto de futuras investigaciones. Por el momento, nuestras hipótesis señalan la relevancia que factores como la interacción entre comunidades en distintos escenarios pudieron tener (García, 2014; Rojo et al., 2008), frente a los planteamientos que defienden la autoexclusión y/o exclusión de alguno de los grupos (Jover y García Atiénzar, 2014).

\section{El registro material de Valmayor XI: presencias y ausencias en la cultura material}

\subsection{La cerámica: estudio comparativo del conjunto cerámico y sus singularidades}

En el Cingle de Valmayor xi la cerámica constituye uno de los elementos más característicos e interesantes de cara a la interpretación del yacimiento. En general, todos los análisis realizados apuntan hacia la perfecta integración de esta colección en el contexto general del Neolítico antiguo en el Bajo Aragón, definido por otros yacimientos excavados en la zona. De hecho, algunas de las piezas son prácticamente idénticas a otras halladas en Costalena 
Relación del peso cerámico por fase

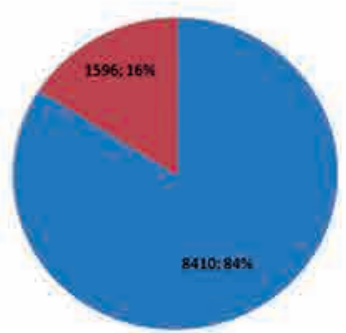

c

Número de recipientes por tipologia y fase

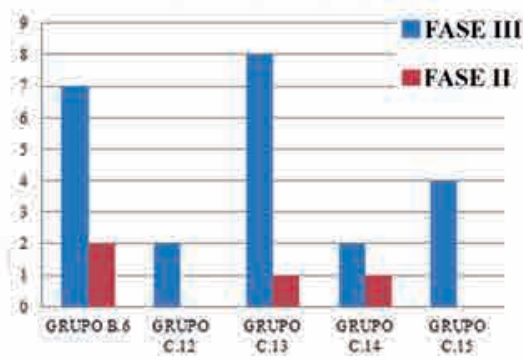

b

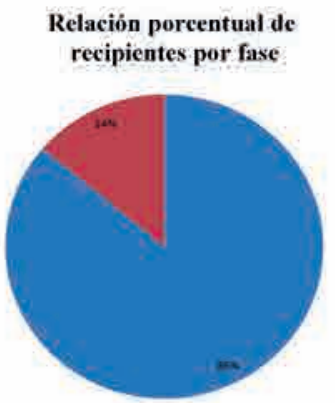

d

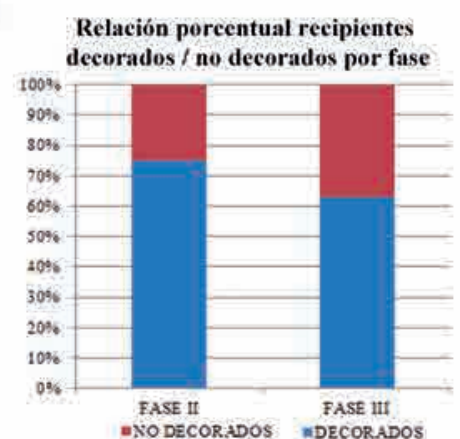

e Número de recipientes decorados $/$ no decorados por tipología y fases
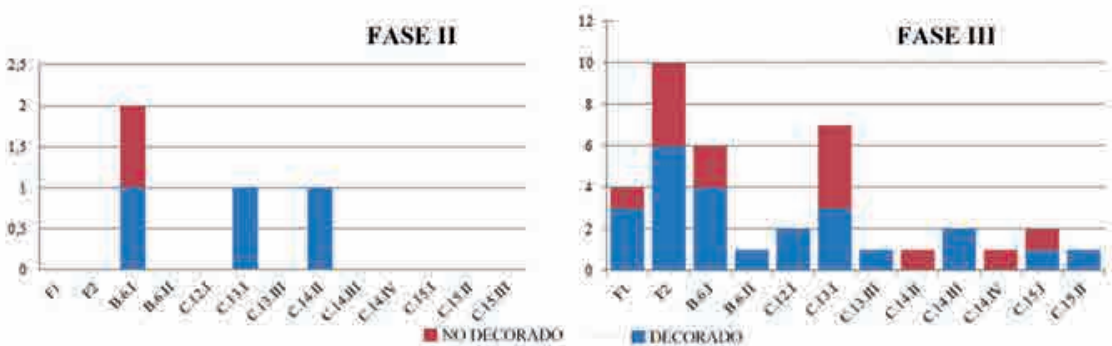

f Téenicas decorativas de los recipientes

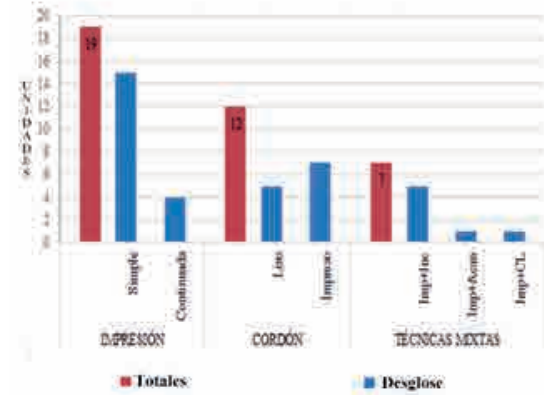

g

g Tipologia de los elementos de prensión por fase

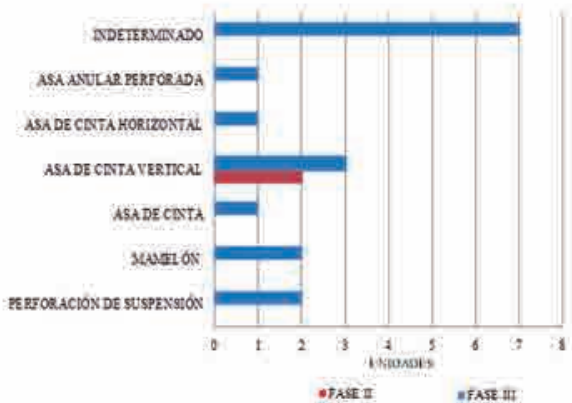

FIG. 5. Gráficos de cuantificación y clasificación del conjunto cerámico por tipología y fases de ocupación (B.6 = cuencos; C.12 = recipientes con cuello/botellas; C. 13 = ollas; C. 14 = contenedores; $C .15$ = orzas y tinajas; $F 1$ = formas abiertas con diámetro de boca igual a diámetro máximo del recipiente; $F 2$ = formas abiertas con diámetro de boca distinto a diámetro máximo). La metodología seguida es la desarrollada por Bernabeu y Molina, 2009.

(Barandiarán y Cava, 1989), Botiquería dels Moros (Barandiarán, 1978) o El Plano del Pulido (Utrilla y Bea, 2011). Los hallazgos cerámicos contextualizados en este yacimiento se restringen a la zona interior protegida bajo la visera del abrigo y a los horizontes ocupacionales más recientes -Valmayor XIII y III-. El análisis realizado de todo el conjunto, atendiendo a distintos aspectos, ha dado lugar a importantes diferencias entre ambos momentos de ocupación.

\subsubsection{Análisis cuantitativo: número de restos y porcentajes}

La excavación ha proporcionado una de las colecciones cerámicas más extensas si la comparamos con los enclaves coetáneos del Bajo Aragón. Se ha recuperado un total de 673 restos frente a los 556 de Costalena, los 519 de Las Torrazas, los 443 de El Pontet o los 290 de Alonso Norte. Una mayor diferencia se observa con respecto a otros núcleos como Botiquería dels Moros o Els Secans -con 45 y 20 fragmentos respectivamente- (Ramón, 2006: 57-69). De este conjunto, 117 piezas proceden de los niveles superficiales y por tanto fueron encontradas fuera de contexto, por lo que no han sido incluidas en los análisis.

La gran diferencia observada en cuanto al número de fragmentos y peso 
porcentual de la cerámica recuperada en las distintas fases (Fig. 5a, b y d) podría responder principalmente a dos cuestiones. En primer lugar, hay que tener en cuenta la distinta cronología de ambos horizontes, puesto que la datación del segundo momento de ocupación es de mediados del VI milenio cal BC, situándolo temporalmente cercano a contextos neolíticos pioneros como es el caso del nivel ib de Chaves, el H19 de Cendres, el viII de Cova d'en Pardo o el 80205 de Mas d'Is (Rojo et al., 2012: 591-597). Por su parte, la fase más reciente con fecha de finales del vi milenio cal вC se corresponde con un momento en el que proliferan los enclaves plenamente neolitizados no sólo en el ámbito del valle del Ebro, sino en muchas partes de la Península Ibérica. En segundo lugar, la diferencia en el número de fragmentos recuperados puede deberse al cambio en los modelos de subsistencia, puesto que en la fase más antigua la cerámica se trataría de un elemento integrado puntualmente en la cultura material a través de diversas estrategias de intercambio; mientras que en aquellas sociedades con un bagaje plenamente neolítico el elemento cerámico ya estaría siempre presente, siendo generalmente de fabricación local.

\subsubsection{Análisis cualitativo: formas y proceso de elaboración}

Todo el conjunto cerámico documentado se integra perfectamente en las pautas generales definidas para este periodo, entre las que destaca el predominio de formas simples. Si bien en Valmayor XI-II tenemos una variedad reducida de tipos, destacando el binomio cuenco-olla, en Valmayor XI-III se ha registrado una mayor diversidad y la introducción de nuevas formas, como los contenedores o botellas característicos del Neolítico antiguo en todo el territorio peninsular. También se observa un aumento significativo de grandes recipientes (Fig. 5c, e y g).

En relación al proceso de elaboración, el análisis se ha centrado en la observación de dos aspectos específicos: las cocciones y los tratamientos de la superficie. Las cerámicas presentan cocciones reductoras y colores oscuros tanto en sus secciones como en sus superficies en Valmayor XI-II, mientras que en la fase posterior este análisis indica una mayor variedad. Según García y Calvo (2006) la homogenización y equilibrio cromático del corte transversal de las paredes de la vasija -característica de las cerámicas de Valmayor XI-II- es reflejo de cocciones largas en atmósferas estables, lo que, unido a una cocción reductora como revela el color de la sección, parece indicar el uso de una estructura aislada y cerrada. Por su parte, los datos de Valmayor XI-III indican que en torno al 80\% de la producción cerámica se coció en una atmósfera estable aunque, a diferencia de la fase anterior, hay un $20 \%$ de casos en los que no es homogénea e incluso algunos ejemplos de 'mala cochura'. En cuanto al tratamiento de las superficies, 3 de los 4 recipientes identificados en Valmayor XI-II tienen la superficie alisada, mientras que el otro tiene un tratamiento más cuidado consistente en el bruñido tanto de la pared exterior como la interior. En Valmayor XI-III, los tratamientos más cuidados, entendiendo por ello el bruñido-espatulado, son anecdóticos puesto que en el $87 \%$ de los casos el acabado de los recipientes corresponde únicamente al alisado. Estos datos apuntan hacia dos situaciones bien diferenciadas. La uniformidad y estabilidad de las cocciones, junto a una dedicación importante en el tratamiento de las superficies, en la fase con cerámica más antigua, manifiestan que los escasos recipientes documentados son de muy buena calidad; sin embargo, en los niveles más recientes se han registrado casos en los que las cocciones son poco uniformes y las superficies no siempre reciben un tratamiento especial, lo que indica una mayor variabilidad en cuanto a la calidad de las cerámicas. Este diferente comportamiento avala la hipótesis de que en un principio la cerámica se trató de un objeto escaso muy valorado y de buena calidad, por lo que podría ser un factor clave en las redes de intercambio. Con el paso del tiempo, el elemento cerámico se generalizó, dejando de recibir el mismo tratamiento de objeto especial para convertirse en una pieza común del ajuar doméstico, dando lugar a la aparición de recipientes con 'mala cochura' y de ciertas imperfecciones como las localizaciones cromáticas específicas.

\subsubsection{Análisis de las decoraciones: técnicas y patrones}

El análisis de las técnicas decorativas también muestra una importante diferencia entre las dos 


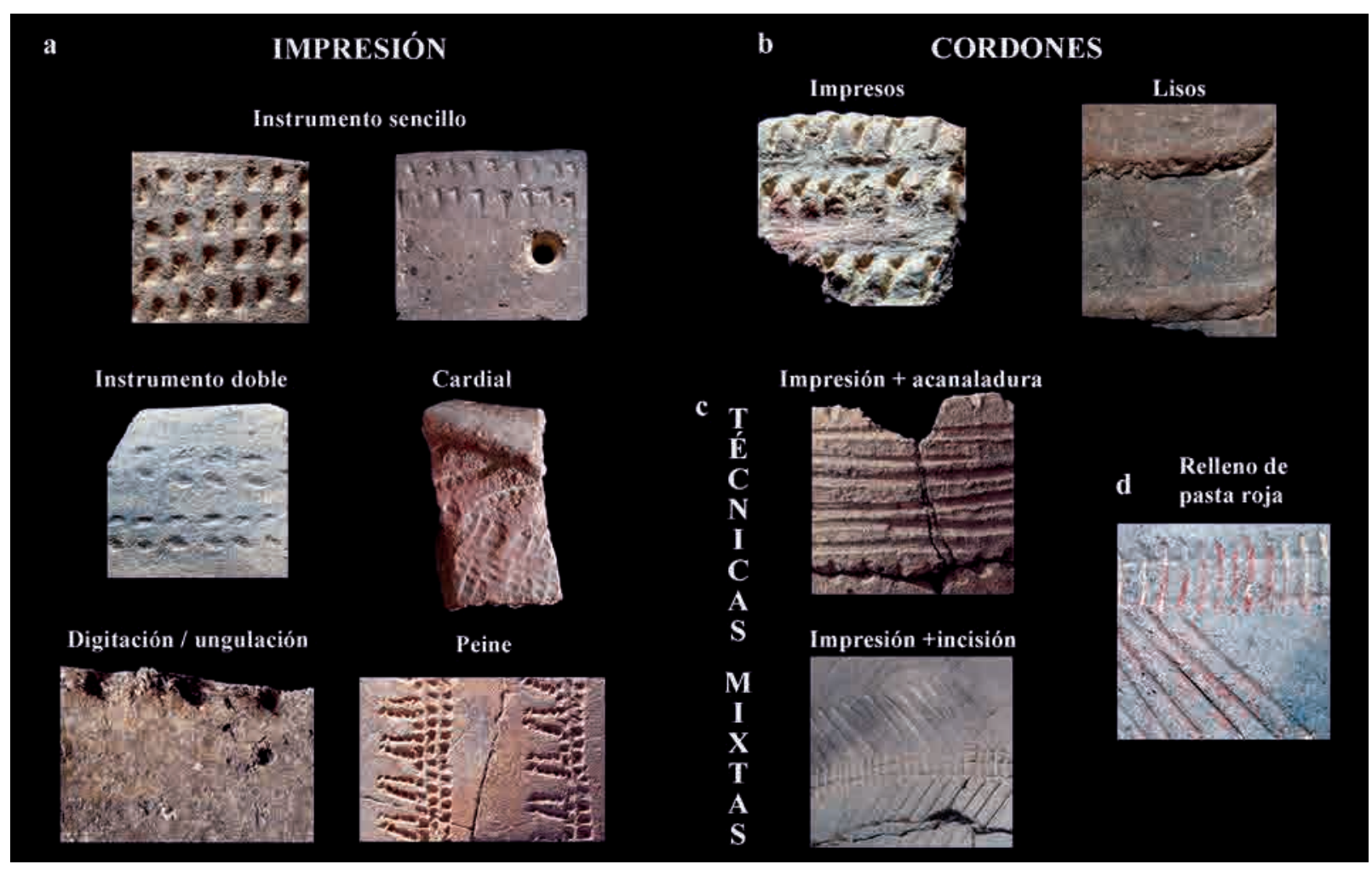

FIG. 6. Detalles de las técnicas decorativas presentes en la colección cerámica.

fases cerámicas, caracterizada por la presencia de una mayor variabilidad en el periodo más reciente.

La técnica mejor representada en todo el conjunto es la 'impresión con instrumento', siendo mayoritaria en ambos niveles aunque con ciertas diferencias (Fig. 4a). En Valmayor XI-II es la única técnica decorativa, representada por piezas con 'impresiones simples' y algún caso con la técnica mixta de 'impresión + acanaladura' (Fig. 6a y c). En Valmayor XI-III el 50\% de los fragmentos decorados están impresos, siendo un 79\% 'impresiones simples' y el resto 'impresiones continuas'. Dentro de este grupo se han identificado tres variantes (Fig. 5f):

- La decoración 'cardial' aparece en 2 fragmentos que presentan ornamentación en el borde, si bien en uno de ellos se combinan además las modalidades de 'arrastre' y 'pivotante' (Fig. 6a). Porcentualmente supone un $5,26 \%$ del total de cerámicas documentadas y el $10,52 \%$ de las 'impresas'. Este dato es similar a Costalena c2 -14,28\%- o Chaves 1a $-21,56 \%-$, pero contrasta con otros yacimientos del Bajo Aragón como Botiquería dels Moros 6
-100\%- y $8-40 \%$-, Costalena c1 -33,33\%- o El Pontet c. sup. $-70 \%-$, así como con otros contextos del valle del Ebro como Forcas II $-43,85 \%-$ o Chaves 1b-51,4\%- (Ramón, 2006: 349).

- La decoración 'a peine' (Fig. 6a) representa el $18,42 \%$ del total registrado y el $36,84 \%$ de las impresiones. Este hecho lo equipara a los yacimientos del Bajo Aragón como Botiquería dels Moros 8 $-40 \%-$, El Pontet c. sup. $-30 \%$ - o Costalena c2 $-35,71 \%-$, y lo diferencia de los enclaves oscenses en los que esta técnica decorativa rara vez sobrepasa el 8\% (ibidem: 349 ).

- La 'digitación/ungulación' (Fig. 6a) se ha documentado en un $5,26 \%$ de los restos y se corresponde con el 10,52\% de las cerámicas 'impresas'. De nuevo, existen varias estaciones en el valle del Ebro que ofrecen datos similares como Alonso Norte -5,88\%-, Las Torrazas -5\%-, Costalena c2 $-7,14 \%-$, la Cueva del Moro de Olvena superior $-19,37 \%$-, Chaves 1a -11,2\%- y $1 \mathrm{~b}-5,39 \%-$ (ibidem: 349) o Els Trocs -15\%-- (Rojo et al., 2013: 27). 


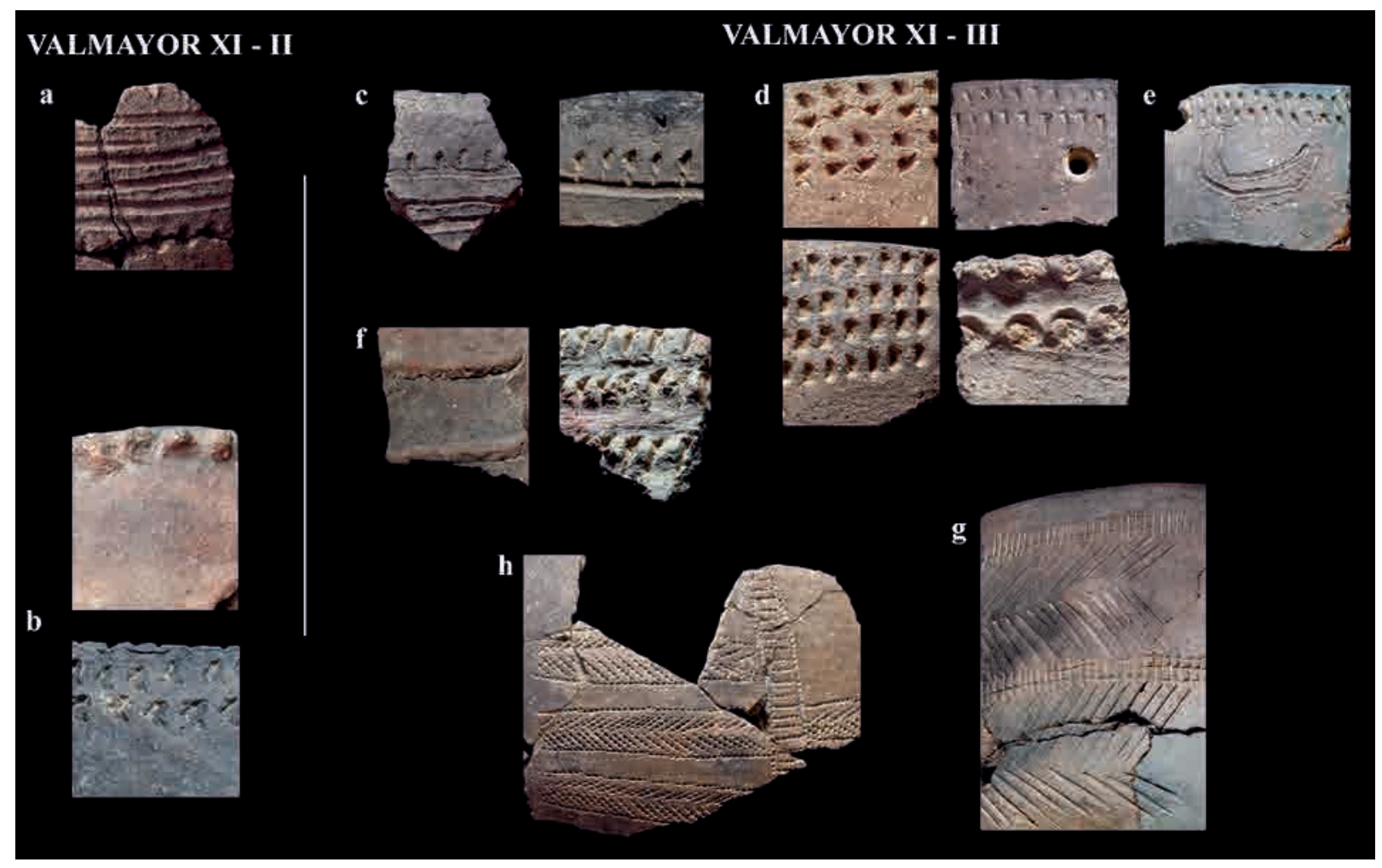

FIG. 7. Selección de algunos motivos y patrones decorativos.

Las restantes técnicas decorativas documentadas en este yacimiento sólo están presentes en el nivel neolítico de ocupación más reciente -Valmayor XIIII-, a excepción de los casos decorados con técnica mixta ya mencionados, hallados en la fase anterior (Fig. 5f). La siguiente técnica en importancia es la aplicación de 'cordones' que corresponde a un $32 \%$ del total (Fig. 6b), rasgo característico de las colecciones del valle del Ebro (García et al., 2011: 91), como indica su alta representatividad en Las Torrazas, El Pontet b, Els Secans, Costalena c, Forcas II, y su papel destacado en lugares como Botiquería dels Moros 8 o Chaves 1b (Ramón, 2006: $348,351)$. Por último, las técnicas mixtas sólo se corresponden con un $18 \%$, constituidas en todos los casos por una combinación de 'impresión' con una segunda técnica, que puede ser 'incisión', 'acanaladura' o 'cordón liso' (Fig. 6c). Hay que destacar, por su singularidad, una pieza decorada mediante esta técnica mixta, en la que además se ha documentado un relleno de pasta roja cubriendo parte de la decoración (Fig. 6d). Es relevante la ausencia total de 'boquique', técnica junto al cardial que más protagonismo interpretativo ha adquirido en los últimos años (Alday, 2009; Alday y Moral, 2011).

A pesar de la falta de estudios experimentales, se han podido extraer algunas conclusiones sobre los posibles instrumentos utilizados en el proceso decorativo. De nuevo, es en el horizonte ocupacional de Valmayor XI-III donde se ha documentado una mayor variedad, identificándose el uso de peines dentados, de espátulas tanto biapuntadas como de sección curva, así como las propias manos manifestadas en la realización de 'digitaciones y ungulaciones'. En algunos casos, se ha podido identificar el empleo de fibras vegetales, entendiendo como tales tallos o hierbas, que evidencia un uso de 'materiales de fortuna' o improvisados. Existen además ejemplares decorados con conchas, dos de ellos con un berberecho-Cerastoderma sp.-y otro con la concha de un gasterópodo, probablemente una Rumina decollata, usada para la realización de impresiones con la parte distal de la misma; probablemente, esta última se tratase también de un "útil de fortuna". Hay 
que destacar el hallazgo de una espátula (Fig. 11a), cuyos análisis tecnológicos han arrojado indicios acerca de su posible utilización sobre arcilla fresca (cf. apartado 3.3.1), hecho que avalaría la hipótesis de la fabricación local de los recipientes cerámicos -o al menos de una parte de ellos- documentados en el horizonte de Valmayor XI-III. En este sentido, algunas de las decoraciones estudiadas podrían perfectamente haber sido realizadas con un instrumento de este tipo (Fig. $7 \mathrm{~g}$ ).

Las pautas metodológicas publicadas en García et al. (2011) son las que se han seguido para el estudio de los patrones decorativos documentados en el Cingle de Valmayor XI. Los resultados obtenidos de nuevo manifiestan una clara diferenciación entre los dos niveles con cerámica, orientada hacia una mayor complejidad y variedad en la decoración de los recipientes recuperados en el horizonte de Valmayor XI-III. El conjunto ornamentado de la fase más antigua se define por la presencia de motivos simples, limitados en todos los casos al tercio superior de las piezas, con los que se han podido determinar dos patrones decorativos distintos caracterizados por líneas horizontales paralelas (Fig. 7a y b). Ejemplos similares se pueden encontrar en el nivel c2 de Costalena (Barandiarán y Cava, 1989: 50-51, figs. 25, n. ${ }^{\text {os }} 6$ y 8 , y 26, n. ${ }^{\text {os }} 2-4$ ), o los niveles 6 y 8 de Botiquería dels Moros (Barandiarán, 1978: 105, fig. 36, n. ${ }^{\text {s }} 4$ y 6). Estas características se ajustan al denominado 'Estilo I' (García et al., 2011: 101) que cuenta con un desarrollo cronológico entre el 6100-5500 cal BC. Por su parte, el conjunto decorativo de Valmayor XI-III es más complejo y variado con respecto a los motivos representados, identificándose diversos patrones que pueden comportar distintas técnicas e instrumentos para su elaboración. En general, presenta muchas de las características del llamado 'Estilo II' (ibidem: 102), como son la complejidad decorativa y la diversidad temática, técnica y compositiva. La horquilla cronológica atribuida a este grupo estilístico es de 5500-5000 cal BC, encajando perfectamente con las dataciones disponibles para la fase más reciente del yacimiento.

Una de las composiciones más habituales de esta fase es la formada por la combinación de líneas horizontales paralelas flanqueadas por encima y/o debajo por filas de trazos o puntos (ibidem: 98) (Fig. 7c). Ejemplos similares de cronologías coetáneas se han hallado en Costalena c2 (Barandiarán y Cava, 1989: 51, fig. 26, n. ${ }^{\text {s }} 5$ y 6), El Pontet c.inf. o Alonso Norte (Ramón, 2006: 160, figs. IIIII), y también en otros lugares más alejados como Chaves, La Espluga de la Puyascada, El Forcón, La Cueva del Moro (ibidem), La Draga (Tarrús, 2008: 25, fig. 10) o Els Trocs (Rojo et al., 2013: 28-29). Otro de los temas documentados, caracterizado por su importante distribución desde el sur de Francia hacia todo el territorio peninsular, es el compuesto por líneas horizontales paralelas realizadas con distintas técnicas (García et al., 2011: 98) (Fig. 7d). En una de las piezas se combina este motivo con 'guirnaldas' subcirculares dispuestas a modo de frisos inferiores (Fig. 7e). Se han registrado paralelos en El Pontet, Alonso Norte (Ramón, 2006: 154, figs. III-IV), Costalena c2 (Barandiarán y Cava, 1989: 50, fig. 25, n. ${ }^{\text {os }} 1,6$ y 8), Forcas II (Montes, 2014: 250, fig. 3, n. ${ }^{\text {os }}$ 9-10), y sobre todo en Chaves, La Cueva del Moro, El Forcón, La Espluga de la Puyascada (Ramón, 2006: 154, figs. I-II y 156, figs. I-III) o Els Trocs (Rojo et al., 2013: 29). Entre la decoración plástica destacan los cordones tanto lisos como decorados con impresiones, que aparecen bien aislados o bien en combinación con otros temas (García et al., 2011: 96-97) (Fig. 7f). Los paralelos más cercanos están documentados en Botiquería dels Moros, El Pontet, Costalena, Els Secans (Ramón, 2006: 168, figs. I-IV y 181, figs. I-II) o Riols I (Royo y Gómez, 1997: 29, fig. 5, n. ${ }^{\text {s }}$ 1,2 y 4; y 30, fig. 6, n.os $1-4$ ), aunque los ejemplares hallados en diferentes zonas geográficas son incontables (Rojo et al., 2013: 31). Por último, destacar la existencia de algunos ejemplos por su complejidad compositiva, teniendo en cuenta que en la mayoría de los casos el desarrollo decorativo está incompleto por lo que resulta complicado adscribirlos a un determinado grupo temático (Fig. $7 \mathrm{~g}$ y h). Uno de estos recipientes (Fig. 7h) cuenta con paralelos similares en yacimientos como El Plano del Pulido (Utrilla y Bea, 2011: 149, fig 4, n. ${ }^{\circ} 17$ ), La Draga (Gibaja y Clop, 2012: 348, fig. 4, n. ${ }^{\circ}$ 6), Chaves (Baldellou, 2011: 143, fig. 4) o Cova de l’Or (Martí, 2011: 185, fig. 3).

\subsection{La industria lítica: un conjunto numeroso y representativo de toda la cadena tecnológico-operativa}

La industria lítica recuperada en el Cingle de Valmayor XI es numerosa y, por lo general, de una calidad excepcional, presentando un buen estado de 
conservación. Los análisis se han centrado en cuestiones relativas a la gestión técnica y económica de las materias primeras y su identificación, a la caracterización técnica y tecno-tipológica de las piezas y, en último término, a la funcionalidad de los útiles.

\subsubsection{Gestión técnica de la industria lítica sobre sílex}

Se trata de una colección lítica en sílex destacada, y lo es en primer lugar por su número, aunque su variedad y buena calidad también quedan patentes. Se han documentado un total de 6258 restos, de los cuales 3941 se encontraron contextualizados: 338 en Valmayor XII, 2632 en Valmayor XI-II -siendo con diferencia la fase con mayor porcentaje cuantitativo-y 971 en Valmayor XI-III. Para la identificación y descripción de los diferentes tipos primarios líticos se ha seguido la metodología de G. Laplace (1986).

En relación a las estrategias de explotación del sílex, los 22 núcleos identificados apuntan hacia la obtención mayoritaria de soportes laminares, evidenciando además una cierta planificación de la inmensa mayoría de las extracciones, perceptible tanto en las facetas que presentan los talones de las láminas como en los negativos observados en los núcleos (Fig. 8, n. ${ }^{\text {os }} 5 \mathrm{y}$ 26). De manera minoritaria,
VALMAYOR XI - I

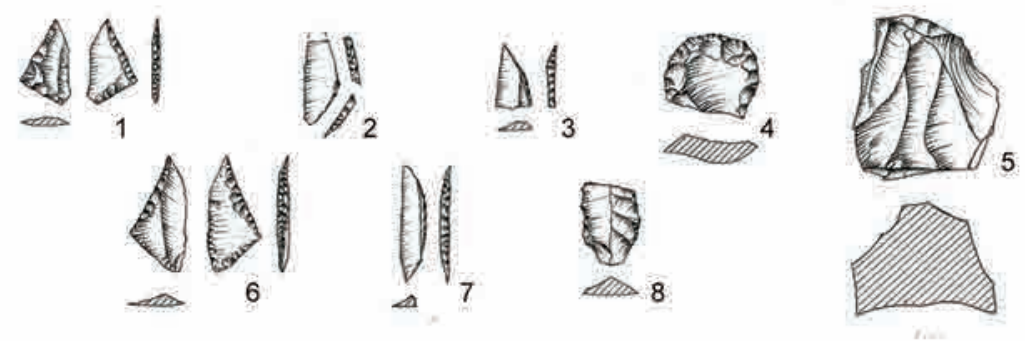

VALMAYOR XI - II
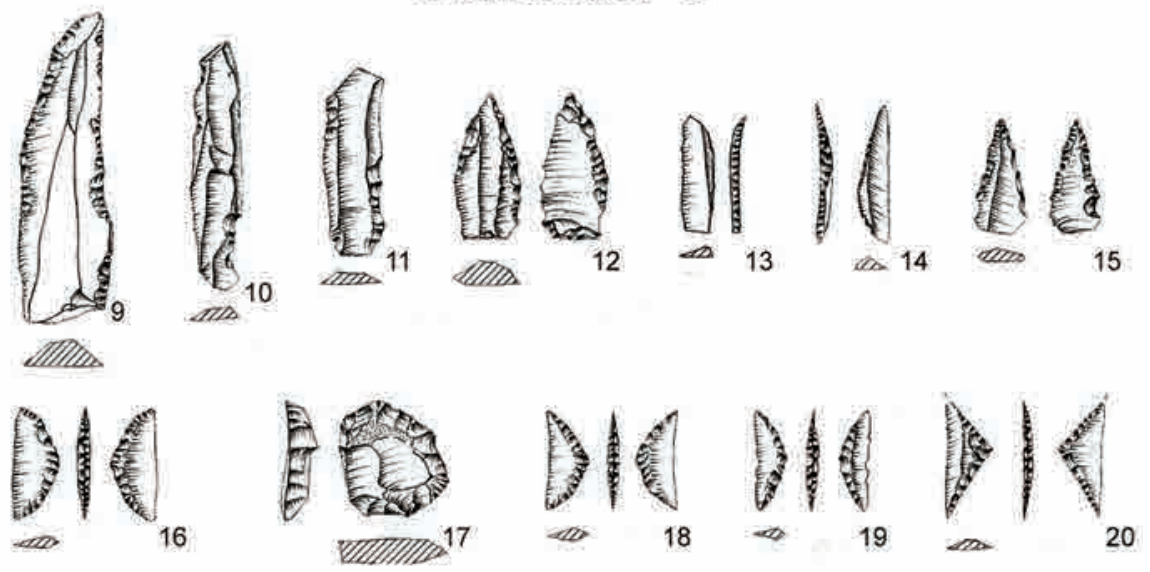

\section{VALMAYOR XI - III}
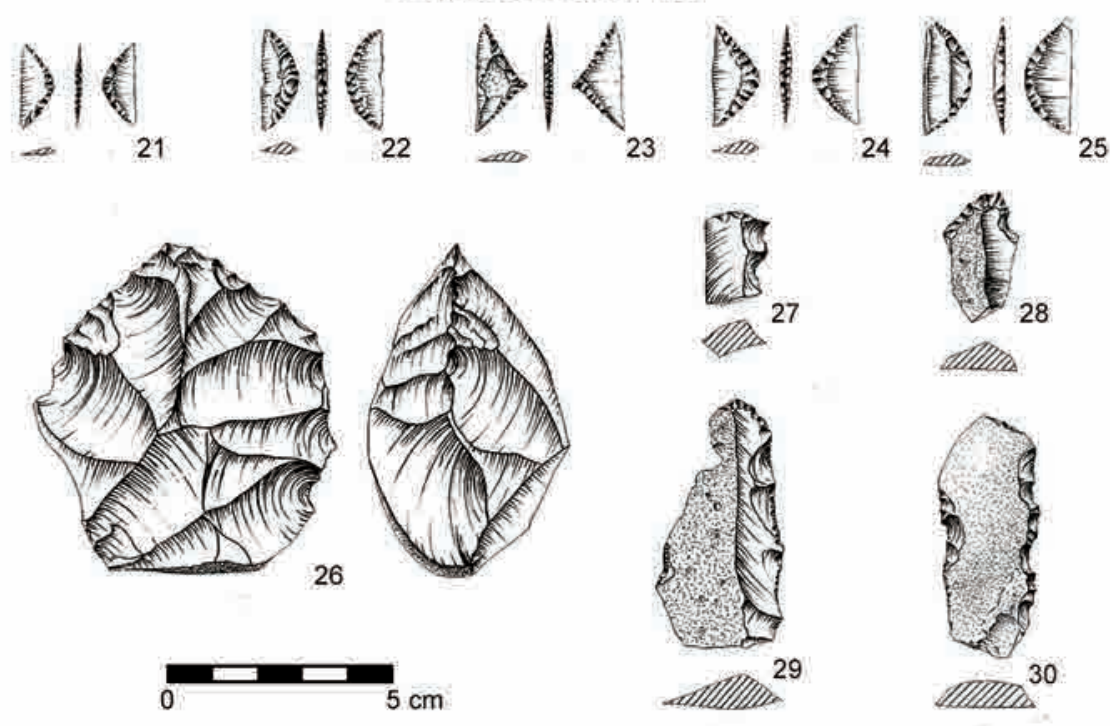

FIG. 8. Selección de piezas de la industria lítica recuperada en las distintas fases de ocupación del yacimiento (dibujo de Á. Rodríguez González). 


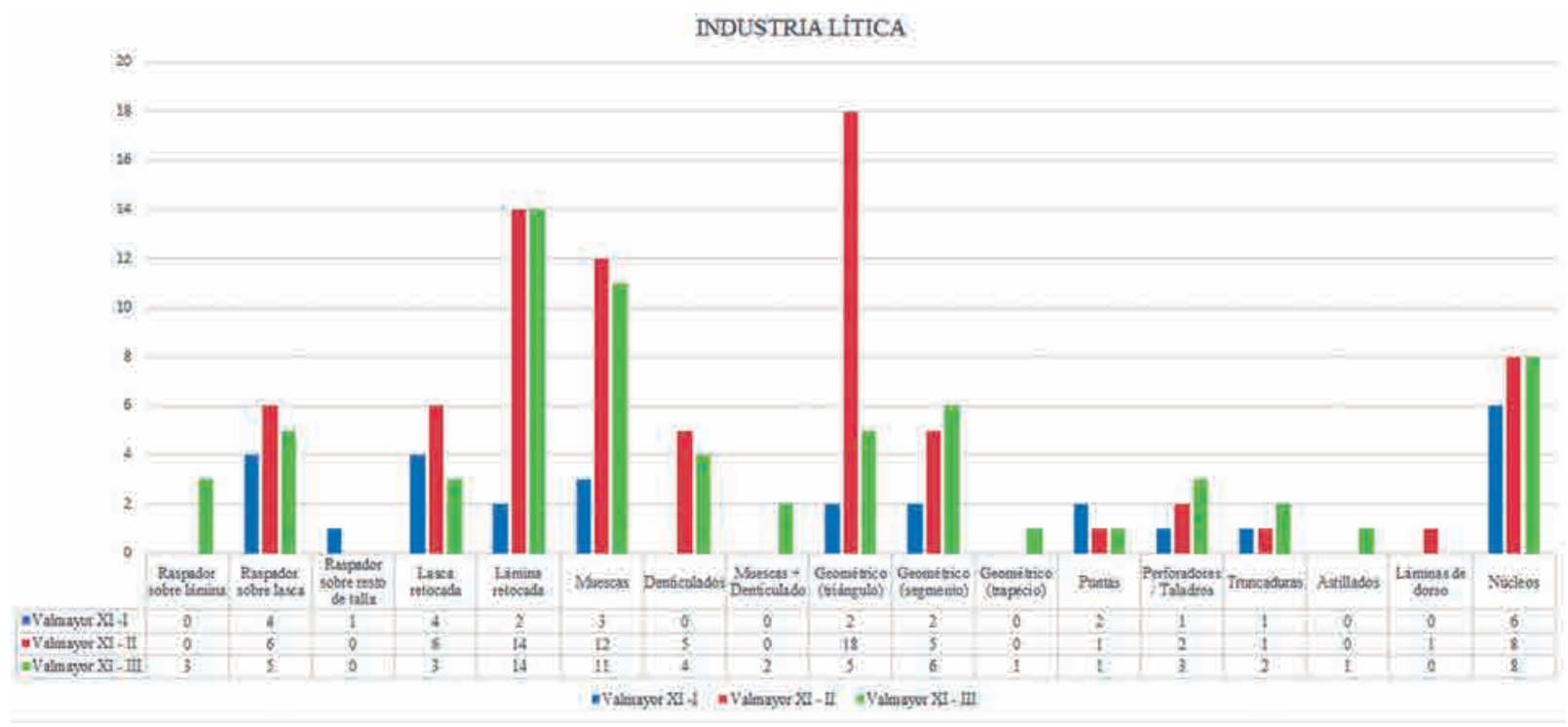

FIG. 9. Diagrama de barras y tabla de clasificación y cuantificación de los tipos de soporte y útiles líticos agrupados según los diferentes momentos de ocupación.

se han hallado núcleos agotados, lascas de gran tamaño y percutores con una o varias extracciones, que manifiestan otro tipo de explotación más orientada a la satisfacción inmediata de una necesidad eventual, sin recurrir a un plan de talla previo. Las casi 300 láminas registradas se enmarcan dentro de un patrón métrico que va de los 20-80 $\mathrm{mm}$ aproximadamente, cuya media de longitud comienza a crecer en Valmayor XI-II con respecto al horizonte anterior, llegando en algunos casos a los 50-60 mm (Fig. 8, n. ${ }^{\text {os }} 8$, 9-11 y 29-30), siendo en Valmayor XI-III cuando se hace patente este hecho ${ }^{2}$. Por tanto, es evidente que de manera gradual comienzan a fabricarse láminas más largas hasta dominar el registro de soportes laminares en la fase más reciente, coincidiendo con la aparición de los primeros fragmentos de cerámica y objetos de ornamento personal. Otra particularidad es que, de manera general, a lo largo de toda la ocupación del abrigo, se seleccionan las láminas más largas para posteriormente ser modificadas mediante retoque, ya sea este continuo, de muescas y/o denticulados,

${ }^{2}$ Se ha priorizado en el análisis el parámetro de la longitud frente a otros como la anchura o el espesor, por considerarlo el más significativo de cara a la interpretación del desarrollo tecnológico y los cambios acaecidos en el mismo durante este momento de transición. o mediante la asociación de diferentes técnicas en la misma pieza (Fig. 8, n. ${ }^{\text {os }} 8,9-11,27$ y 29-30).

El número total de útiles identificados es de 154 (Fig. 9). Todas las evidencias parecen apuntar a que las labores de talla y retocado se realizaron en el propio yacimiento, puesto que se han hallado piezas en diferentes estadios de elaboración, además de ejemplares reiteradamente reavivados y reparados tras haber sufrido dańos y fracturas. Los dos tipos de útiles específicos más representativos de esta colección han resultado ser los raspadores y los geométricos:

- Raspadores: aunque no se han documentado grandes diferencias cuantitativas entre las distintas fases (Fig. 9), constituyen una herramienta interesante para observar la dinámica interna de la producción lítica en el abrigo, puesto que mientras en los dos momentos más antiguos de ocupación el soporte elegido para fabricar este tipo de útil fue la lasca, en el más reciente se constata la introducción de la lámina para su elaboración (Figs. 9 y 8 , n. ${ }^{\text {os }} 4,17$ y 28). Independientemente del horizonte ocupacional, el tipo mayoritario es el raspador frontal frente a otros como el ojival, el de hocico o el de retoque fronto-lateral, cuya presencia se registra a partir del segundo horizonte ocupacional en el primer caso y del nivel más reciente en el resto 
(Fig. 8, n. ${ }^{\text {os }} 17$ y 28). Otras formas como el raspador circular aparecen en el horizonte más antiguo del yacimiento y continúan de manera marginal en la siguiente fase, para terminar desapareciendo posteriormente (Fig. 8, n. ${ }^{\circ}$ 4). Por tanto, se observan ciertos cambios sustanciales en la dinámica interna de la tecnología de los raspadores, pero sin grandes rupturas a lo largo de toda la ocupación prehistórica. Una particularidad documentada en un buen número de piezas, sin distinción del tipo ni del horizonte en el que fueron encontradas, es la presencia de un acusado desgaste en la zona activa de los raspadores, fruto de un continuo reavivado con el fin de mantener el frente en óptimas condiciones para su uso. Por tanto, a pesar de la proximidad y facilidad de acceso a la materia prima, los pobladores del Cingle de Valmayor XI prefirieron optar por el empleo recurrente y prolongado del instrumental lítico en lugar de fabricar nuevas piezas.

- Geométricos: en términos relativos, teniendo en cuenta el factor de superficie excavada ${ }^{3}$, este tipo de útil es más numeroso en los momentos más tempranos de la ocupación, reduciéndose posteriormente su número de manera acusada (Fig. 9). Su tipología responde a las formas de triángulo y segmento, con una relación porcentual variable según el horizonte ocupacional de que se trate (Figs. 9 y 8, n. $\left.^{\text {os }} 1-3,6-7,14,16,18-20,21-25\right)$, con la excepción de un posible trapecio en fase de fabricación. En este sentido, es relevante destacar el hallazgo de 2 segmentos o medias lunas en Valmayor XI-I (Fig. 8, no ${ }^{\text {os }} 2$ y 7), nivel que se corresponde con un contexto preneolítico, cuando tradicionalmente se ha relacionado este tipo de geométrico con un cambio en las estrategias socioeconómicas ligado a la neolitización del Bajo Aragón (Utrilla et al., 2009). La presencia de esta tipología aumenta cuantitativamente en el siguiente periodo ocupacional -aunque en minoría con respecto a los triángulos-, y acaba siendo predominante en los momentos más recientes (Fig. 9). Además, se da una bajada acusada en el número de triángulos entre las dos últimas fases, lo que podría estar ligado a una desaparición progresiva de este tipo en pro de otro hasta entonces minoritario como el segmento. La misma interpretación se puede dar a la observación de una tendencia en estos mismos útiles hacia la

3 Cf. apartado 2; hay que recordar que los niveles más antiguos se han documentado en un área muy pequeña. convexidad de sus catetos -al menos en un $25 \%$ de las piezas- (Fig. 8, n. ${ }^{\text {s }} 20$ y 23), lo que indica una cierta continuidad en los procesos de talla y a su vez la evolución progresiva de los tipos. En cuanto a las técnicas de retoque, la mayoritaria es el doble bisel, con representación del retoque abrupto sólo en tres casos -2 en Valmayor XI-I y 1 en Valmayor XI-II-, ninguno de ellos procedente de las cronologías más recientes (Fig. 8, nos 2,7 y 14). Llama la atención el hallazgo de 2 triángulos con retoque bifacial en Valmayor XI-I (Fig. 8, n. ${ }^{\text {s }} 1$ y 6 ), puesto que esta técnica ha sido considerada tradicionalmente como 'genuinamente neolítica'. Se han hallado algunos paralelos en contextos similares como Botiquería dels Moros 4, donde este tipo de elementos han aparecido asociados a niveles en los que también se han registrado geométricos de 'tipo Cocina' (Alday et al., 2012c: 326; Domingo, 2004: 78; Utrilla et al., 2009: 146). De nuevo, estos datos no encajan con los patrones cronotipológicos establecidos para la zona (Utrilla et al., 2009), apoyando la hipótesis de una continuidad sin rupturas en las técnicas de talla para la elaboración de proyectiles, y en general del resto de útiles, y de una evolución progresiva de los tipos fabricados.

En conclusión, a pesar de constatarse ligeros cambios en los soportes o en las estrategias de talla a lo largo de la estratigrafía, estos se han ido incorporando de manera gradual y en ningún momento suponen una ruptura significativa en el procesamiento de las materias primas minerales. Por tanto, existe una clara continuidad en las estrategias de talla sólo alterada por la probable aplicación de ciertas mejoras técnicas, que significaron una mayor rentabilidad en los procesos y/o un aumento de la productividad en el uso de las piezas.

\subsubsection{Traceología y gestión funcional de la industria sobre sílex}

Se ha llevado a cabo una primera aproximación a la funcionalidad del utillaje lítico analizando un total de 146 piezas, 25 de ellas procedentes del nivel superficial y por tanto fuera de contexto, con el objeto de evaluar la conservación global del yacimiento. La selección del material para su estudio traceológico se ha fundamentado en criterios como su estado de conservación, la presencia de 


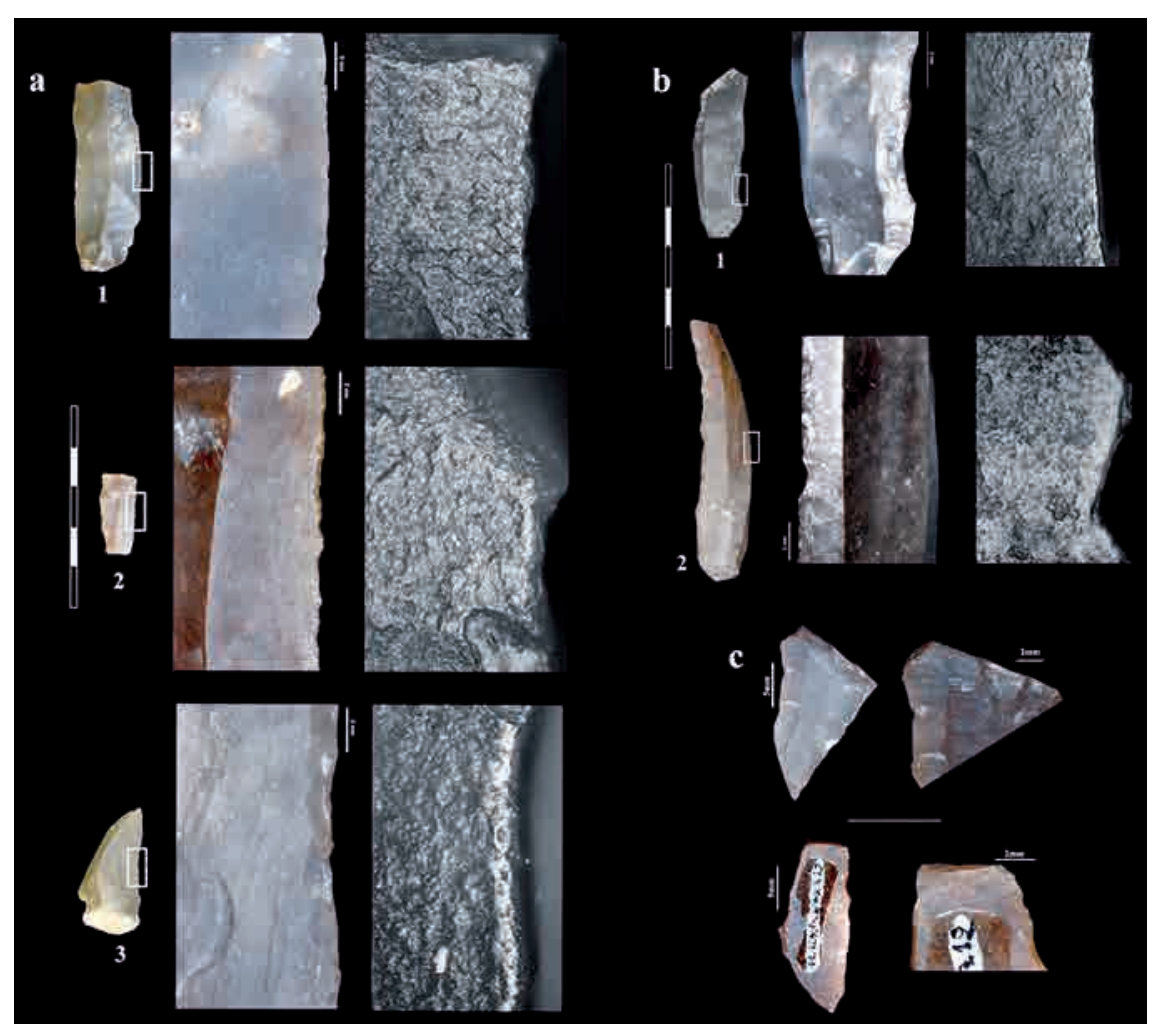

FIG. 10. Estudio traceológico: a) útiles de UE 14 empleados para descarnar (1), cortar piel seca (2), raspar hueso (3) -fotografías con microscopio a 200X-; b) lámina de UE 6 usada para raspar hueso (1) y de UE 1 utilizada para cortar plantas, probablemente cereales (2) -fotografías con microscopio a 100X-; c) geométricos de UE 14 con fracturas de impacto.

filos potencialmente utilizables, el tamaño de las piezas -desechándose lascas inferiores a $1,5 \mathrm{~mm}$ salvo en casos de fragmentos de útiles mayores- y la modificación de alguna zona mediante retoque - pero también se han seleccionado productos no retocados-. En general, la conservación del material lítico recuperado en Valmayor XI es excepcional, lo que se refleja en la ausencia de piezas 'no analizables' y en la escasez de soportes considerados como 'sin criterio', en los que se registran modificaciones pero se desconoce si son o no de uso. Sólo de manera puntual se ha detectado alguna pieza ligeramente patinada en los niveles de superficie, más expuestos a la erosión, y otros casos ya en niveles contextualizados que muestran huellas macroscópicas superficiales resultantes de una alteración térmica. Debido al escaso número de piezas analizadas es muy difícil elaborar hipótesis sólidas sobre la funcionalidad del conjunto lítico documentado. En este sentido, ciertas cuestiones, como si hay o no diferencias entre las actividades económicas desarrolladas a lo largo de todas las ocupaciones, el papel que jugaron los instrumentos líticos en las tareas de producción, los criterios que se siguieron a la hora de seleccionar los útiles o si la función de cada uno de los niveles de asentamiento identificado fue similar, aún no han podido ser respondidas.

Sin embargo, parece que el abanico de actividades que se llevaron a cabo es amplio. Se han constatado instrumentos destinados tanto a la obtención y procesado de materias animales, como al trabajo de productos vegetales, e incluso en una ocasión al raspado de un elemento mineral (Fig. 10a y b). También se perfilan algunas evidencias interesantes como es el papel destacado de los útiles de carnicería en los niveles más antiguos -Valmayor XI-I-, la importancia del trabajo sobre hueso en los momentos posteriores y el empleo de materias vegetales en el horizonte más reciente. Precisamente, es en Valmayor XI-III donde se ha documentado la única pieza que presenta unos micropulidos quizás vinculados con el corte de cereales (Fig. 10b.2), hecho que encajaría perfectamente con la interpretación de este nivel como un contexto ya plenamente neolitizado. En relación al tipo de soporte utilizado según la actividad realizada, se ha podido apreciar que los instrumentos empleados para descarnar o cortar piel y plantas no leñosas son láminas sin retocar de filos agudos, mientras que las muescas se han usado para el raspado de materias óseas; en cambio, para el trabajo sobre elementos abrasivos como la piel o la madera se han buscado instrumentos de distinta morfología, retocados o 
no, pero con ángulos más bien obtusos que fueran resistentes y efectivos. Por su parte, los geométricos se han destinado sistemáticamente a actividades cinegéticas (Fig. 10c), hecho que se constata en otras zonas peninsulares tanto en cronologías mesolíticas como neolíticas (Gibaja y Palomo, 2004). Por último, hay que señalar que puntualmente se han empleado los filos corticales para el raspado de materias vegetales o piel.

\subsubsection{Caracterización de la industria macrolítica}

La colección macrolítica es un conjunto relativamente bien conservado, cuya presencia se limita a los dos momentos de ocupación prehistórica más recientes, sin grandes diferencias cuantitativas entre ambos. Hay que señalar que una buena parte de estos elementos aparecieron en superficie, y por tanto completamente descontextualizados. Precisamente fue en este nivel superficial donde se recuperó, en perfectas condiciones de conservación, la pieza más destacada de todo el conjunto, una azuela pulimentada y elaborada sobre un tipo de roca metamórfica negra.

En relación al resto de la colección, destaca la industria fabricada sobre cuarcita, tanto por su número como por su variedad. Se han documentado 4 manos de molino de mediano tamaño, con al menos una de sus caras alterada por medio de abrasión o desgaste y, en algunos casos, con los extremos fragmentados y repiqueteados, posiblemente como resultado de su uso como herramienta para machacar. Además, se ha constatado que algunas de estas piezas estuvieron sometidas a altas temperaturas, lo que podría explicar su estado de fragmentación. Todo este conjunto procede de la fase más reciente de ocupación del abrigo -a excepción de una de ellas que fue recuperada en el nivel superficial-, hecho que encaja perfectamente con los resultados de otros análisis realizados sobre el material lítico ( $c f$. apartado 3.2.2.) que, de la misma forma, vinculan los posibles eventos de cultura material asociados al procesado de cereal exclusivamente con este horizonte ocupacional. También sobre cuarcita se han registrado otro tipo de artefactos como percutores o alisadores, con numerosas huellas de uso. Por otra parte, se han recuperado objetos realizados sobre granito, arenisca e incluso bloques de caliza de una gran diversidad funcional, aunque difícil de determinar. Dentro de este grupo destacan 2 ejemplares de morfología alargada y plana, elaborados sobre arenisca y con profundas acanaladuras en la superficie, rasgos que han permitido identificarlos como afiladores sobre los que se friccionaban distintos materiales para conseguir un mejor acabado de la pieza. Ambos se encontraron en superficie, por lo que no se han podido adscribir con seguridad a un periodo concreto de ocupación. En cuanto a su funcionalidad, hay diferentes planteamientos que van desde su empleo en la fabricación del utillaje óseo, en el procesamiento de materias vegetales (Edo et al., 2011), hasta su uso en la preparación de los astiles de madera para enmangar los proyectiles -en algunos yacimientos europeos tipo turbera como Stellmoor, Roc de la Tour II o Sablonmere, han aparecido elementos similares asociados a conjuntos de fustes de flecha- (Utrilla y Mazo, 1991).

Por otra parte, se han documentado otro tipo de elementos macrolíticos, asociados más a un ámbito ornamental o ritual que propiamente funcional. Se trata de un extenso grupo de cantos rodados de cuarcita de mediano tamaño, con la superficie alisada y algunas huellas de uso poco significativas, cuya particularidad estriba en que en muchos casos aparecen impregnados con restos de pigmento rojizo o incluso en alguna ocasión grabados. Posiblemente, la presencia de ocre sea resultado del empleo de estas piezas como herramientas para el procesado y/o aplicación de esta sustancia, más que como soportes de la misma. También se hallaron algunos fragmentos de este pigmento natural a lo largo de la excavación.

\subsection{La industria ósea y los elementos de adorno}

\subsubsection{La industria ósea: un pequeño conjunto 'polifuncional'}

La colección de piezas realizadas sobre material óseo no destaca por su interés cuantitativo, pero sí por su buena calidad, lo que ha permitido obtener unos interesantes resultados a través de los estudios de las evidencias de los procesos tafonómicos, las técnicas de manufactura -huellas tecnológicas- y sus aplicaciones funcionales -huellas de uso-. 


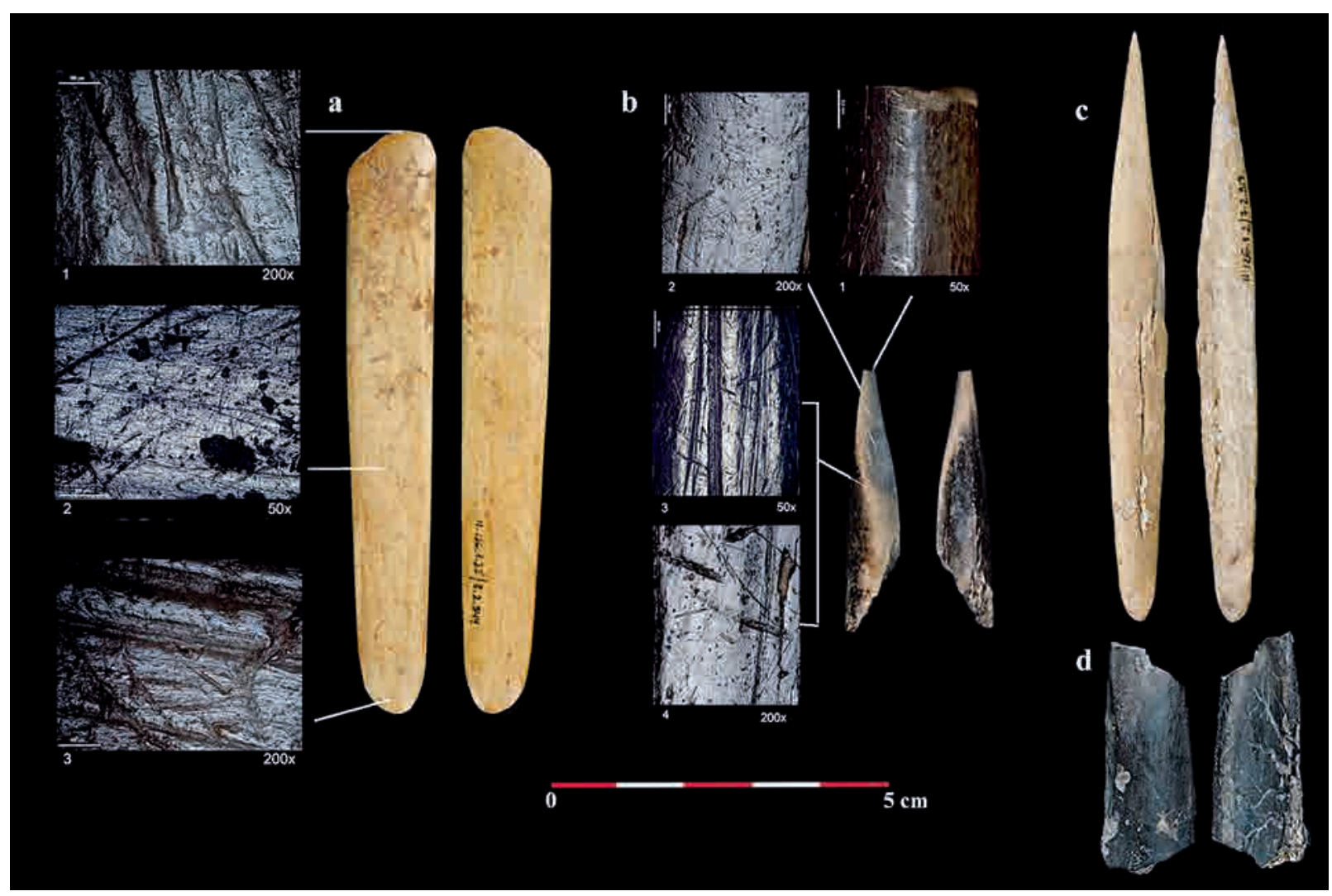

FIG. 11. Conjunto óseo de Valmayor XI-II (b) y XI-III (a, c y d) y estudio tecnológico de algunos útiles: a) espátula de UE 1 con huellas de uso (2) y micropulidos (1 y 3), caracteristicas del trabajo sobre arcilla fresca; b) punzón de UE 6 con huellas de uso por perforación sobre piel (1 y 2) y materia vegetal (3 y 4) -fotografias con microscopio a 12-70X-

La industria ósea documentada en este yacimiento se limita a 4 piezas (Fig. 11) procedentes de la fase prehistórica más reciente-Valmayor XI-III-, a excepción de una de ellas que fue recuperada en los niveles del horizonte cronológico anterior. La mayor parte de estos objetos muestran huellas de manufactura y/o de uso y responden a diferentes tipos normalizados de utillaje. Se han registrado 2 punzones, la única forma presente en ambos momentos de ocupación (Fig. 11b y c). La pieza hallada en la fase más reciente (Fig. 11c) se trata de un objeto apuntado, que presenta huellas de pulido en la zona del ápice y estrías tecnológicas de manufactura en la mitad proximal y en la cara dorsal. Su comparación con el material experimental sugiere que se empleó sobre materia vegetal, lo que podría vincularse a una actividad textil y/o de cestería. En cuanto al otro punzón, recuperado en el horizonte de Valmayor XI-II (Fig. $11 b)$, se ha observado una fuerte alteración térmica que afectó irregularmente a toda la superficie y estrías transversales concentradas en la zona más próxima al ápice. Esto indica una acción de perforación que combina movimientos de rotación y punción, que podría corresponderse con las evidencias de realizar dicha acción sobre piel (Fig. 11b.1 y b.2), mientras que las de la zona mesial del fragmento son similares a los estigmas experimentales de trabajo sobre materia vegetal (Fig. 11b.3 y b.4). Es posible, por tanto, que un mismo útil se utilizara para realizar distintas actividades, siendo en este sentido la perforación en piel la última de las funciones realizadas. Otro de los tipos de utillaje óseo registrado es una espátula corta y ancha, completamente trabajada y muy bien conservada (Fig. 11a). En este caso, las estrías tecnológicas aparecen por casi todo el soporte (Fig. 11a) y está completamente cubierto de un pulido más o menos intenso. Las huellas de uso, concentradas en ambos extremos, corresponden a 
un movimiento sobre todo transversal en el extremo proximal y, por el contrario, longitudinal en el extremo distal. No se puede determinar de forma categórica la materia trabajada, pero por la disposición del micropulido y sus características (Fig. 11a.1 y a.3) podría tratarse de arcilla fresca para la elaboración de cerámicas (Maigrot, 2010) ${ }^{4}$. La última de las piezas es un fragmento mesodistal de un útil con sección plano-convexa, que podría responder al tipo bien de punzón bien de espátula, con una fuerte alteración térmica (Fig. 11d) que dio lugar a la aparición de una pátina brillante por toda la superficie. Esto unido al posterior desgaste tafonómico postdeposicional ha impedido que los estudios realizados permitan concretar su funcionalidad.

Los resultados de los

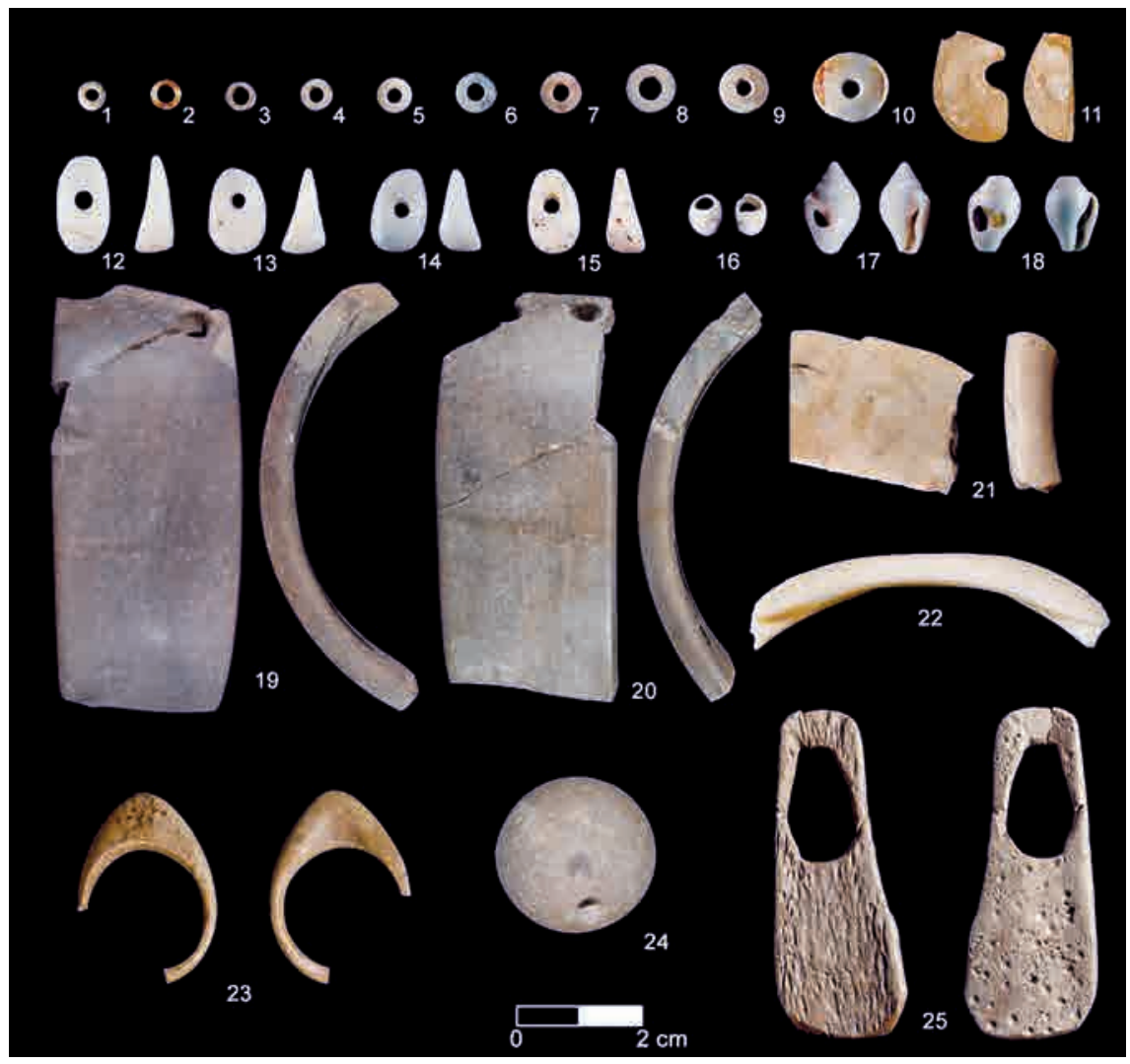

FIG. 12. Selección de elementos de adorno recuperados en las fases de Valmayor XI-II y III, y en el nivel superficial.

análisis de la industria ósea evidencian una compleja historia tafonómica que combina diversos agentes y procesos. Destacan los factores antrópicos puesto que además de las huellas de carnicería, tecnológicas y de uso, hay indicios de fracturas en estado fresco. También la alteración térmica por cremación parcial se ha constatado en varios de los objetos, lo que sugiere que los utensilios tras el término de su vida útil fueron amortizados en un hogar o integrados en alguna estructura de combustión con posterioridad de manera involuntaria. Entre los procesos postdeposicionales, están presentes fundamentalmente las alteraciones por disolución, tanto por contacto con el agua filtrada por los propios sedimentos como por la acción de

${ }^{4}$ Cf. también Maigrot, Y.: Étude technologique et fonctionnelle de l'outillage en matières dures animales la Station 4 de Chalain (Néolithique final, Jura, France). Tesis doctoral presentada en 2003 en la Univ. PanthéonSorbonne de Paris. raíces. Atendiendo a la funcionalidad de la pequeña muestra de utillaje óseo analizada, el conjunto parece caracterizarse por la diversidad de tareas en las que se utilizaron estos utensilios -incluyendo el trabajo sobre materias animales, vegetales y cerámicas- y por los indicios de polifuncionalidad en algunos de ellos.

\subsubsection{Los elementos de adorno: un singular conjunto ornamental}

La numerosa colección de elementos ornamentales, que asciende a 54 piezas, se caracteriza por la diversidad de sus formas y materias primas sobre las que se fabricaron. Todo el conjunto, al igual que en el caso de la industria ósea, se documentó en las fases más recientes de ocupación prehistórica -Valmayor XI-II y III-, sin grandes diferencias entre ellas salvo por la presencia/ausencia de algunos tipos singulares. 
Destacan por su número aquellos elementos definidos como cuentas de collar o colgantes, en función de su morfología y tamaño (Fig. 12, n. ${ }^{\text {s }}$ 1-18). Las más numerosas son las cuentas de collar discoides -34 ejemplares en total- de pequeño tamaño, realizadas sobre conchas de bivalvos que han podido identificarse en algunos casos como Cardiidae (Fig. 12, n. ${ }^{\text {os }} 1-10$ ). Sobre este mismo material se han documentado 9 colgantes denominados de tipo lágrima, con la superficie completamente pulida (Fig. 12, n. ${ }^{\text {os }} 12-15$ ). Por su forma y tamaño, recuerdan en algunos casos a dientes de ciervo -en concreto, a caninos atróficos-, lo que lleva a considerarlos como "elementos de imitación". Dentro de este grupo también se incluyen 5 conchas que han sido perforadas cerca del labro (Fig. 12, n. ${ }^{\text {os }}$ 16-18), en su gran mayoría de la especie Columbella rustica -salvo en un caso que se utilizó un gasterópodo fluvial, Teodoxus fluviatilis-, y un fragmento de Dentalium procedente del momento de ocupación más reciente del abrigo. Estos adornos a base de conchas perforadas se han documentado en varios yacimientos con cronologías neolíticas del valle del Ebro -Costalena, El Pontet, Cueva del Moro de Olvena, Forcas II Riols I...-, aunque también están presentes en contextos mesolíticos (ÁlvarezFernández 2008). A todo este conjunto hay que sumar el hallazgo de un fragmento de cuenta globular confeccionada sobre calcita, rota al hacer la perforación, en el horizonte ocupacional de Valmayor XI-III (Fig. 12, n. ${ }^{\circ} 11$ ).

Esta colección de objetos ornamentales se completa con una serie de elementos más excepcionales. En primer lugar, hay que destacar la presencia de varios fragmentos de brazalete, que corresponden a 4 ejemplares diferentes, realizados a su vez sobre diversas materias primas que incluyen mármoles de distintos colores (Fig. 12, n. ${ }^{\text {os }}$ 19-21). Algunos de estos fragmentos presentan perforaciones, en ocasiones inacabadas, posiblemente necesarias para adaptar la pieza a la muñeca del portador. Existen algunos paralelos en el valle del Ebro, en yacimientos como la Cueva del Moro de Olvena o El Torollón (Alday, 1995). A este grupo hay que añadir un fragmento de brazalete recuperado en la fase más reciente de la ocupación, confeccionado a partir de una concha de gran tamaño, posiblemente de la familia Glycymerididae (Fig. 12, n.o 22). Varios objetos de este tipo fueron documentados en el cercano yacimiento de Riols i (Royo y Gómez, 1992 y 1997). El diámetro de la pieza no es demasiado grande, por lo que sería un posible adorno para una persona con una muñeca no demasiado gruesa, quizás una mujer o un niño. Por otro lado, hay que destacar el hallazgo de 2 piezas excepcionales por su factura y singularidad, ambas realizadas sobre hueso. Por una parte, un anillo conservado casi completamente y en muy buenas condiciones (Fig. 12, n. ${ }^{\circ}$ 23), elaborado posiblemente sobre la epífisis de un hueso largo. El tratamiento y acabado mediante bruñido de la pieza le aporta una gran calidad. Se conocen algunos paralelos en estaciones como la Draga, Can Sadurní, Mas del Pla (Bernabeu et al., 1989) y Cova Fosca (Barranchina, 1996) que permiten contextualizarlo en cronologías neolíticas antiguas, aunque este fue recuperado en el nivel superficial del abrigo. La otra pieza excepcional se trata de una placa rectangular fabricada a partir del fragmento de una costilla de animal, con un gran orificio en uno de los extremos que permite utilizarlo como colgante y con decoración de numerosos círculos de pequeño tamaño en su cara dorsal realizados mediante rotación de una punta lítica (Fig. 12, n. ${ }^{\circ}$ 25). En este caso, el hallazgo se realizó en pleno contexto arqueológico, dentro del horizonte cronológico de Valmayor XI-III. Destaca también el descubrimiento de un esferoide de calcita, posiblemente pulido, que presenta dos perforaciones convergentes inacabadas, lo cual permite plantear su papel como un proyecto de colgante sin terminar (Fig. 12, n. $\left.{ }^{\circ} 24\right)$. Por último, hay que señalar la presencia de conchas de diferentes tipos -fundamentalmente de náyade- a lo largo de toda la estratigrafía del abrigo que, si bien no presentan ningún tipo de modificación, sí pueden considerarse de aporte antrópico y por tanto podrían haber servido en algunos casos de motivo ornamental.

A través del estudio de este conjunto de adornos tan diverso se ha podido plantear la existencia de posibles redes de intercambio y/o comunicación. Por una parte, la presencia de elementos con un claro origen foráneo, como las Columbellae perforadas, el Dentalium, o algunas de las cuentas de collar y colgantes realizados sobre concha, es una evidencia clara de la existencia de vías de contacto hacia la costa mediterránea. En este mismo sentido, podrían interpretarse los hallazgos de los brazaletes de mármol y pectúnculo. Partiendo de esta idea, 


\begin{tabular}{|c|c|c|c|c|c|c|c|c|c|c|}
\hline \multirow{2}{*}{\multicolumn{11}{|c|}{ HC1 }} \\
\hline & & & & & & & & & & \\
\hline ROCA MADRE & - & 6 & - & - & 22 & - & 10 & 4 & 4 & - \\
\hline NIVEL DE OCUPACIÓN & - & - & - & - & 1 & - & 7 & 7 & 55 & - \\
\hline HC2 & & & & & & & & & & \\
\hline NIVEL DE OCUPACIÓN & - & 33 & - & 3 & 546 & - & 201 & 58 & 585 & 1 ave \\
\hline CUBETA & - & - & - & - & 9 & - & - & - & 7 & - \\
\hline HOGAR & - & - & - & - & 2 & - & 1 & - & - & - \\
\hline HC3 & & & & & & & & & & \\
\hline NIVEL DE OCUPACIÓN & 1 & 65 & 1 & 2 & 516 & 19 & 273 & 58 & 599 & 1 ave, 1 reptil \\
\hline HOYO & - & - & - & - & 11 & - & 5 & 3 & 27 & - \\
\hline HOGAR & - & - & - & - & - & - & - & - & 1 & - \\
\hline TOTAL $(n=3145$ & 1 & 104 & 1 & 5 & 1107 & 19 & 497 & 130 & 1278 & 3 \\
\hline$\%$ & $<1$ & 3 & $<1$ & $<1$ & 35 & 1 & 16 & 4 & 41 & $<1$ \\
\hline \% DETERMINADOS & $<1$ & 8 & $<1$ & $<1$ & 89 & 2 & & & & \\
\hline
\end{tabular}

Fig. 13. Tabla de clasificación y cuantificación de los taxones faunisticos agrupados según los diferentes momentos de ocupación de Valmayor XI: vacuno (BOS); ciervo (CEE); cabra (CAH); jabali (SUS); conejo (ORC); lince (LIN); macromamífero (LSM); mesomamifero (MSM); indeterminado (IND); aves y reptiles (OTROS).

se podría afirmar la existencia de una red de intercambios bastante consolidada ya desde un momento muy temprano del fenómeno de la neolitización en el Bajo Aragón, como demuestra el hallazgo de este tipo de objetos en las dos fases de ocupación insertas en dicho fenómeno -Valmayor XI-II y III-. Pero no todos los elementos de adorno habrían sido importados sino que también algunos de ellos serían de fabricación local, como demuestran aquellos objetos que no están acabados por completo o los realizados sobre ciertas materias primas más accesibles -como es el caso del yeso o la calcita, que con mucha probabilidad proceden de afloramientos cercanos al abrigo-.

\subsection{Análisis del registro faunistico y carpológico}

\subsubsection{El registro faunístico: una colección pequeña pero diversificada}

El conjunto faunístico recuperado en el yacimiento ha proporcionado un total de 3145 restos -sin incluir los procedentes del nivel superficial-, de los que apenas 3 no pertenecen a mamíferos, y entre los que destaca la abundancia de conejo. El estado de conservación no siempre ha permitido realizar identificaciones taxonómicas, pero sí anatómicas, por lo que se han creado dos categorías artificiales para los mamíferos de acuerdo con el tamaño -macro- y mesomamíferos-. La categoría de macromamífero incluye mayoritariamente restos de ciervo, mientras que la de mesomamífero agrupa huesos de animales de medio porte, representados en este yacimiento por cabra, jabalí y lince. Los dos restos de ave y el pequeño fragmento de caparazón de Quelonio -tortuga- no resultaron identificables. Las fracturas recientes producidas durante la excavación, almacenamiento y transporte constituyen el proceso tafonómico más frecuente después de las termoalteraciones, sin observarse mordeduras de carnívoros o roedores, y con una baja incidencia de huesos con superficies erosionadas como consecuencia de exposiciones prolongadas anteriores al enterramiento (Lyman y Fox, 1989).

El mayor volumen de material se ha recuperado en las fases de Valmayor XXI-II y III, con representación de al menos cuatro especies de ungulados - uro, ciervo, cabra y jabalí-, una de carnívoro -lince- y una de lagomorfo -conejo-. Los conejos constituyen el mayor porcentaje de la muestra y el taxón dominante en todos los momentos de ocupación del abrigo, siendo el ciervo la segunda especie en importancia, seguida de manera testimonial por el lince, jabalí, uro y cabra (Fig. 13). Concretamente, en el horizonte ocupacional más reciente es donde 
se ha documentado la mayor biodiversidad, caracterizándose por la presencia de un gran porcentaje de Cervus elaphus y por los restos recuperados de Bos primigenius, Capra sp. y Lynx pardina, siendo este último el único carnívoro identificado. Por su parte, la muestra procedente del momento de ocupación más antiguo es escasa, determinándose apenas la presencia de ciervos y lagomorfos (Fig. 13).

A pesar de lo reducido del conjunto analizado, pueden plantearse algunas conclusiones. La mayor frecuencia de conejo en contextos de transición entre cronologías mesolíticas y neolíticas, en ocasiones, se ha interpretado como un indicador de cambios en la dieta asociados a la caza de especies de pequeñas dimensiones (Stiner et al., 1999 y 2000). Sin embargo, es importante tener en cuenta que las acumulaciones de lagomorfos en yacimientos arqueológicos son polémicas, puesto que no siempre tienen un origen antrópico (Lloveras et al., 2008a, 2008b y 2009). En este caso, evidencias como el predominio de adultos, la abundancia de restos termoalterados y de diáfisis de huesos largos y fragmentos no determinados, así como la práctica ausencia de vértebras y costillas (Hockett, 1995), parecen corresponderse con el perfil de las estrategias antrópicas de depredación y adquisición de presas de pequeña talla, descartando la intervención de depredadores animales como agentes responsables de su acumulación. Partiendo de esta idea, el hecho de que en los niveles de Valmayor XI-III se acumularon menos restos de conejo en proporción a los ungulados que con respecto a la fase de ocupación anterior (Fig. 13), unido a la mayor variedad de especies identificadas, sugiere una cierta diversificación de los recursos explotados a finales del vi milenio cal BC y un papel más destacado de los mamíferos de gran porte en la dieta de los pobladores.

Por otra parte, la presencia de animales jóvenes (Payne, 1987; Silver, 1969) entre las especies de ungulados -ciervo, jabalí y cabra- indica la disponibilidad y aprovechamiento de los mismos, y por tanto un cierto carácter estacional del asentamiento. Los perfiles anatómicos de estas mismas especies (Binford, 1978), además del lince, sugieren el transporte selectivo de determinados elementos relacionados con el procesamiento y curtido de pieles (Ibáñez et al., 2002), aunque no se han observado marcas de corte ligadas a tareas de desollado o despiece -excepto en una de las dos primeras falanges de una pezuña de jabalí recuperada en Valmayor XI-
III-. Esta actividad podría haberse desarrollado de forma puntual durante el verano, y en ella habrían tenido un papel importante las estructuras de combustión identificadas (Almeida et al., 2009). También la escasez de restos faunísticos es compatible con la hipótesis de ocupaciones breves y esporádicas del lugar.

\subsubsection{El registro carpológico: la explotación de los recursos silvestres}

Gracias a la metodología seguida a lo largo de la excavación, que contemplaba el muestreo sistemático de todo el sedimento para su posterior flotación y triado -se han flotado aproximadamente 10840 l-, se ha podido recuperar un importante volumen de restos antracológicos diversos. En el presente trabajo, se van a exponer los resultados obtenidos del estudio de las evidencias carpológicas, puesto que los análisis de la restante colección antracológica aún están en proceso de elaboración. Los taxones que se han identificado corresponden mayoritariamente a frutos y en menor medida a semillas, recuperándose también un destacado conjunto de hojas fundamentalmente de romero, sabina negra y de forma puntual acículas de enebro (Fig. 14, n. ${ }^{\circ} 18,20 \mathrm{y}$ 21). Los frutos más abundantes son las núculas de lentisco y las de terebinto, junto a brácteas de algunas piñas muy mal conservadas que podrían proceder de pino carrasco. En menor medida aparecen restos de bellotas y semillas de enebros (Fig. 14, n. ${ }^{\text {os }}$ 6, 10 y 13-15); y puntualmente de madroño, brionia, acebo, endrino y vid (Fig. 14: 2 y 4). Entre las escasas semillas identificadas (Fig. 14, n. ${ }^{\text {os }} 1,3,7$, 8 y 17) hay algunas cariópsides de poáceas -Avena sp. y Phalaris sp.- y restos de otras plantas -como Galium sp.-, apareciendo igualmente evidencias de distintas leguminosas -Medicago/Melilotus- y lamiáceas -Ajuga cf. Reptans o búgula y Teucrium sp.-. Hay que destacar la ausencia total de taxones domésticos identificados.

En relación al comportamiento diacrónico de este tipo de eventos, es importante señalar que están representados en las tres fases de ocupación, sin grandes diferencias entre ellas salvo el pequeño porcentaje de restos procedentes del nivel más antiguo, hecho que puede estar vinculado a la escasa representatividad del mismo en el conjunto estratigráfico global. Por tanto, atendiendo al registro 
carpológico se podría plantear una hipótesis de continuidad en las actividades desarrolladas a lo largo del tiempo en el abrigo. Varias de las especies de frutos y semillas identificadas pueden tener una vinculación con la alimentación de los usuarios del abrigo, como por ejemplo las bellotas, un recurso muy explotado hasta la actualidad dada su calidad como alimento, su facilidad de recolección y de almacenamiento y su abundancia (Mason, 1992; McCorriston, 1994; Zapata, 2000)5. También las bayas de los madrońos, especie muy extendida por todo el territorio peninsular, son dulces y pueden ser consumidas directamente (Rivera y Obón de Castro, 1991: 509), al igual que los frutos de los endrinos o de las vides. Por su parte, algunas de las cariópsides de gramíneas documentadas, como las avenas, también podrían haber sido un importante complemento de la dieta, ya que aparecen con cierta frecuencia en contextos de grupos cazadores-recolectores, como en el caso alicantino de Coves de Santa Maira (Aura et al., 2005). El modo de empleo de otras de las especies identificadas, como las núculas de lentisco y terebinto o los frutos de los enebros/sabinas, es más difícil de determinar. A pesar de que todos ellos son susceptibles de ser consumidos, e incluso en

5 También Antolín, F.; Alonso, N.; López, V.; Pérez Jordà, G. y Zapata, L.: Mesolithic plant use in the Iberian Peninsula, en prensa.

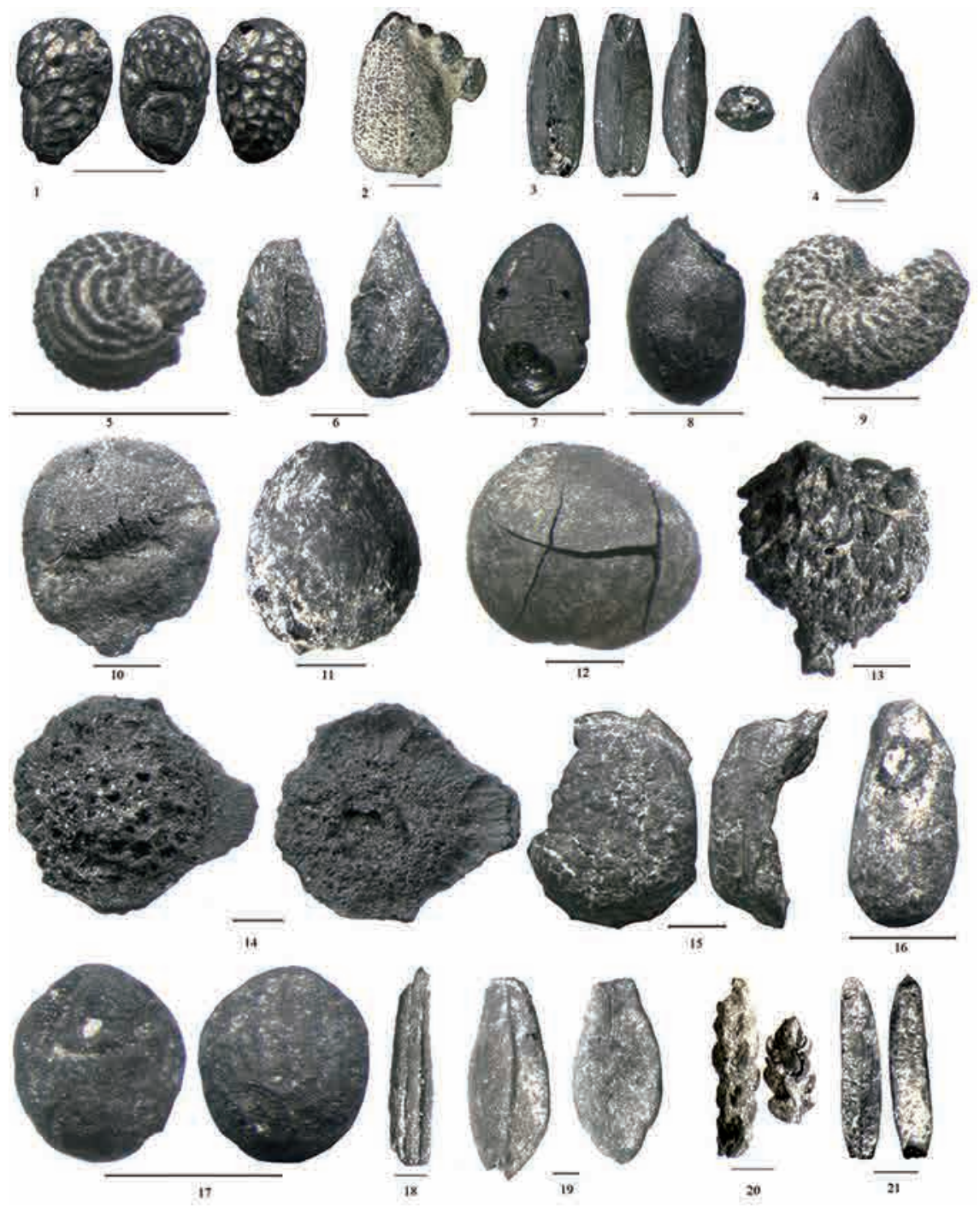

FIG. 14. Detalles de los restos carpológicos: 1) Ajuga $c f$. Reptans; 2) Arbutus unedo; 3) Avena $s p$.; 4) Bryonia dioica; 5) Caryophyllacea; 6) Juniperus $c f$. communis; 7) Medicago sp.; 8) Phalaris sp.; 9) Reseda odorata/phyteuma; 10) Pinus sp., bráctea; 11) Pistacia terebinthus; 12) Pistacia lentiscus, 13-15) Quercus sp.; 16) Rosmarinus officinallis; 17) Teucrium sp.; 18) Rosmarinus officinallis, hoja; 19) indeterminada, hoja; 20) Juniperus phoenicea, hoja; 21) Juniperus cf. communis, hoja. los primeros casos está documentado su uso para la extracción de aceite (Rivera y Obón de Castro, 1991) y/o la transformación en harinas, son materiales que con frecuencia se recolectan como leña, por lo que la carbonización de estos frutos pudo ser consecuencia de su adherencia a las ramas en el 
momento de ser utilizados como combustible (ibidem). Lo mismo ocurre con las pińas, puesto que se trata de un material bueno como combustible, pero cuya presencia puede estar al mismo tiempo vinculada con el aprovechamiento de sus semillas (Badal, 1998), ricas tanto en grasas como en proteínas y azúcares.

Por otro lado, algunos de los taxones presentes en el registro carpológico de este yacimiento pudieron ser utilizados como curtientes por su alto contenido en taninos, como es el caso de la sabina, el terebinto, las hojas de madroño o los frutos de la brionia (Rivera y Obón de Castro, 1991). Este tipo de evidencias, unidas a otros indicios detectados en los análisis faunísticos ( $c f$. apartado 3.4.1), parecen apuntar hacia el procesamiento de pieles como una de las actividades desarrolladas en el Cingle de Valmayor XI. Otros restos documentados como las semillas de Ajuga reptans o las Caryophyllaceae (Fig. 14, n. $^{\text {os }} 1$ y 5), los frutos venenosos como el acebo o la brionia (Fig. 14, n. ${ }^{\text {4 }}$ ) o ciertas leguminosas tienen una interpretación más compleja orientada siempre hacia su presencia en clave accidental como el resultado de la recolección de combustible (Rivera y Obón de Castro, 1991).

En resumen, los pobladores del yacimiento mequinenzano de Valmayor XI no alteraron demasiado el entorno vegetal, limitándose a la recolección de algunos frutos comestibles y al posible aprovechamiento como curtientes de ciertas especies, hipótesis que además está refrendada por la ausencia completa de taxones domésticos en el registro carpológico de todas las fases de ocupación del abrigo.

\section{Valmayor XI como referente en el contexto de la neolitización del Bajo Aragón y el valle del Ebro}

\subsection{Modelos interpretativos sobre la neolitización en el Bajo Aragón}

La mayor parte de los planteamientos acerca de la introducción de las formas de vida neolíticas en la región del Bajo Aragón en particular y del valle del Ebro en general se han caracterizado por tener un cierto cariz indigenista, minimizando la relevancia que ciertos fenómenos de colonización e interacción pudieron tener, y ofreciendo un protagonismo casi absoluto a los grupos mesolíticos locales. Los investigadores que defienden esta tendencia interpretativa basan sus argumentos en distintas evidencias:

- La continuidad estratigráfica y cronológica: en gran parte de los yacimientos excavados de esta región, los niveles identificados como neolíticos culminan amplias estratigrafías de cronologías mesolíticas. La consideración de dichos contextos habitacionales como propios de economías productoras viene dada por la presencia de algunos elementos de cultura material, a pesar de que no existan apenas variaciones con respecto a las ocupaciones anteriores en relación a las estrategias subsistenciales o de explotación del territorio. En este punto, ha sido especialmente utilizado el argumento de la 'funcionalidad' de los distintos yacimientos para defender que una comunidad neolítica, que ocupa estacionalmente un campamento especializado para la caza $u$ otras actividades (como pueden ser los abrigos), no requiere de la misma cantidad de ciertos artefactos propios de las economías productoras como cerámicas o animales domésticos, puesto que en ese contexto no los necesita (Alday, 2006; Alday et al., 2012a y b; Barandiarán y Cava, 2000; Montes y Alday, 2012).

- La aparición paulatina de los 'marcadores neolíticos': como ya se ha apuntado, la simple presencia de algunos de los elementos de cultura material considerados parte del package neolítico, se considera una evidencia cierta de hallarse ante una ocupación de grupos neolitizados. El 'fósil-guía' por excelencia en este sentido es la cerámica, que suele aparecer en pequeñas cantidades cuando se trata de contextos del vi milenio cal $\mathrm{BC}$ ubicados en abrigos con ocupaciones mesolíticas anteriores, con excepción de algunos yacimientos como Mendandia, Atxoste (Alday, 2006) o el propio Valmayor xi (cf. apartado 3.1). También algunos rasgos de las colecciones de talla lítica -el predominio de la talla laminar, la presencia de geométricos segmentiformes, el retoque en doble bisel o el aumento de las láminas de dorso y su posterior decaimiento hasta desaparecer- se han interpretado como "genuinamente neolíticos" e indicadores de un cambio tecnotipológico vinculado a las nuevas formas de vida (Alday, 2006; Barandiarán y Cava, 2001: 143-145; Cava, 2000: 104-108 y 2006: 236-239; Montes y Alday, 2012: 54; Utrilla, 2002: 190). 
- La continuidad en la ocupación y explotación del territorio: al definir este tipo de contextos como neolíticos, se ofrece una imagen de continuidad en relación a las estrategias de ocupación del territorio, puesto que según estos modelos interpretativos las nuevas formas de vida fueron ganando terreno progresivamente, pero mientras aún se mantenía la misma red de yacimientos (Alday, 2006; Montes y Alday, 2012), sin rupturas ni discontinuidades.

En los últimos años, se han presentado algunos planteamientos que matizan en cierta medida estas hipótesis continuistas, en los que, a pesar de que se siguen considerando este tipo de contextos como neolíticos, se introduce ya la idea de la existencia de posibles contactos e intercambios "en el seno de una economía todavía epipaleolítica" (Utrilla et al., 2009: 168-173). A pesar de estos y otros matices interpretativos (Alday, 2009: 159), todos estos enfoques siguen dando preeminencia a una perspectiva material en sus planteamientos, sin atender al conjunto de transformaciones que tuvieron lugar con la llegada del Neolítico en la esfera socioeconómica y cultural, y no sólo en el ámbito tecnológico.

\subsection{Valmayor XI: ¿un modelo interpretativo diferente para el fenómeno de la neolitización en el Bajo Aragón?}

La intervención llevada a cabo en el Cingle de Valmayor XI y la lectura de su secuencia estratigráfica, cronológica y material permiten plantear un nuevo marco interpretativo sobre el fenómeno de la neolitización en el Bajo Aragón y por extensión del valle del Ebro. Se han documentado ciertos hallazgos que distorsionan en cierta medida la imagen continuista y unilineal planteada tradicionalmente para esta región, y que han llevado a cuestionarse la adscripción temporal de ciertos elementos considerados 'genuinamente neolíticos'. En este sentido, destaca la aparición tanto de monturas geométricas segmentiformes como de otros microlitos retocados mediante la técnica del doble bisel en los niveles más antiguos del abrigo -Valmayor XI-I- (Fig. 9 y Fig. 8, no ${ }^{\text {os }} 1$ y 6) de los que, a pesar de no tener dataciones absolutas, todas las evidencias apuntan hacia su cronología plenamente mesolítica (cf. apartado 3.2.1.). Este hecho vuelve a poner en valor algunas afirmaciones que aseguraban que ..."el doble bisel podría ser un elemento adoptado por grupos cardiales en un lógico marco de trasferencia con poblaciones de base epipaleolítica"... (Juan Cabanilles, 1992: 266). Por otro lado, la presencia de cerámica en niveles en los que no se asocia con ningún otro evento que pudiera considerarse como parte del package neolítico, como es el caso del horizonte cronológico de Valmayor XI-II, hace replantearse no ya su consideración como artefacto neolítico, pero sí el hecho de que sus usuarios desarrollaran unas formas de vida propias de economías productoras (cf. apartado 3.1).

Teniendo en cuenta estos factores, y muchos otros que se han ido exponiendo a lo largo de todo el artículo, se propone la siguiente interpretación para los tres momentos de ocupación identificados en el Cingle de Valmayor XI ( $c f$. apartado 2):

- Valmayor XI-I: se trata de la fase más antigua del abrigo conformada por varios niveles de poblamiento mesolítico, probablemente con cronologías de inicios del vi milenio cal BC. A la espera de futuras intervenciones, el tamaño reducido del área de excavación donde se han documentado dichas ocupaciones y la escasez de eventos arqueológicos recuperados no permiten aportar mucha información por el momento.

- Valmayor XI-II: todas las evidencias apuntan hacia su definición como un "contexto mesolítico con elementos neolíticos", resultante de la interacción entre las comunidades de cazadores-recolectores que ocupaban el lugar y los grupos de productores presentes ya en la región. La completa ausencia de taxones domésticos tanto animales como vegetales, la presencia de recipientes cerámicos de gran calidad probablemente obtenidos mediante intercambios y la continuidad observada en los procesos de talla lítica, entre otros factores, avalan la interpretación de este horizonte ocupacional como un 'nivel de neolitización' en el que las relaciones entre ambos tipos de comunidades son la clave para explicar el desarrollo de este proceso de transformación.

- Valmayor XI-III: a pesar de que ciertos rasgos propios de la etapa anterior se mantienen -como la ausencia de taxones domésticos-, este horizonte se puede considerar ya como un contexto plenamente 
neolítico por diversas razones. En primer lugar, la datación disponible para este nivel se integra perfectamente dentro del marco cronológico establecido para el Neolítico antiguo en el valle del Ebro (Fig. 15), en el que están representados yacimientos que cuentan con todas las evidencias propias de una economía productora consolidada, como Chaves, la Cueva del Moro, Els Trocs o La Draga, entre otros. También en este caso la cultura material es determinante, fundamentalmente en lo que respecta al registro cerámico que experimenta un aumento cuantitativo importante, una diversificación tanto formal como del acabado de las piezas (cf. apartado 3.1.2) y un cambio estilístico significativo que lo asimila al denominado 'Estilo II' (García et al., 2011: 102) (cf. apartado 3.1.3). La horquilla cronológica atribuida a este grupo estilístico es de 5500-5000 cal BC, encajando perfectamente con las dataciones disponibles para este momento de ocupación del abrigo. Otros elementos materiales que avalan la definición de este contexto como neolítico es la presencia de utillaje óseo, de ciertos elementos de adorno como brazaletes o anillos ( $c f$. apartado 3.3.2) o de herramientas de molienda que, junto a una pequeña lámina con micropulidos característicos de los útiles para cortar cereal, son las únicas evidencias de posible actividad agrícola recuperadas en este yacimiento ( $c f$. apartado 3.2.2).

Partiendo de esta secuencia cronoestratigráfica y de las ideas expuestas en ella, se plantea un nuevo panorama para el fenómeno de la neolitización en el Bajo Aragón y por extensión en el valle del Ebro que, lejos de seguir una tendencia unilineal y progresiva, contempla la intervención de diferentes agentes en distintos momentos (Fig. 15) (García, 2014 y 2015; Rojo et al., 2008):

- Grupos 'neolíticos colonos pioneros': fueron los responsables directos de la introducción del Neolítico, portadores de los nuevos conocimientos y formas de vida. En el valle del Ebro se han documentado varios contextos que, por sus condición de fundaciones ex novo, podrían encajar dentro de esta categoría, como en el caso de Chaves, Peña Larga, Can Sadurní y, tal vez, la Bauma del Serrat del Pont. En todos ellos se han obtenido dataciones que van aproximadamente desde el 5700-5600 hasta el 5400-5300 cal вс (Rojo et al., 2012: 591-595).
- Grupos 'mesolíticos con elementos neolíticos': resultantes de la interacción entre comunidades de cazadores-recolectores y las primeras economías productoras. Su desarrollo cronológico es similar al de los 'colonos pioneros', como demuestran las dataciones del propio horizonte de Valmayor XI-II (Fig. 4) y de otros contextos como Aizpea III, Forcas II-V y vi o Mendandia II y iIIsup (Fig. 15) (Rojo et al., 2012: 591-592).

- Grupos 'plenamente neolitizados': a partir del 5300-5200 cal вС se registra en gran parte del territorio peninsular una proliferación de yacimientos, que evidencian ya el final del fenómeno de la neolitización y el inicio propiamente del Neolítico antiguo (Fig. 15). En este momento, el poblamiento se articula en torno a asentamientos al aire libre de fundación ex novo con una clara orientación agroganadera y a campamentos estacionales especializados en actividades como la caza, el pastoreo o la explotación de ciertos recursos naturales, entre otras. En cuanto a estos últimos, algunos son también de nueva planta - casos como El Plano del Pulido cg o Los Husos i y ir en el valle del Ebro (García, 2014 y 2015; Rojo et al., 2012)-, mientras que en otras ocasiones se siguen ocupando aquellos lugares que tradicionalmente habían sido usados por las poblaciones locales, como ocurre en Valmayor XI-III (Fig. 4) y en otros contextos como el Abrigo del Ángel 1-8bsup y 2-2a1, La Peña d.sup., El Pontet c.inf., Els Secans iIa o Botiquería dels Moros 6 (Fig. 1) (Alday et al., 2012c; García, 2014 y 2015; Rojo et al., 2012).

Por tanto, la excavación y estudio del Cingle de Valmayor XI han permitido reformular una serie de parámetros que podrían resumirse en los siguientes puntos:

1. Se ha de cuestionar la identificación de contextos simplemente a través de la presencia de ciertos elementos materiales considerados tradicionalmente como 'marcadores neolíticos' puesto que, como se ha demostrado en el caso de la industria lítica, en realidad no se dio una verdadera ruptura tecnotipológica con respecto al periodo anterior, sino que esos rasgos considerados como novedosos se tratarían de aportaciones de las poblaciones locales mesolíticas 
a lo largo del fenómeno de la neolitización. En este mismo sentido, la presencia de algunos fragmentos cerámicos tampoco es prueba irrefutable para hablar de comunidades neolitizadas, puesto que pueden ser artefactos que se han integrado en la cultura material a través de relaciones de intercambio. Por tanto, para definir un yacimiento como neolítico no sólo puede atenderse a la presencia y/o ausencia de ciertos rasgos técnicos o artefactos, sino que la neolitización dio lugar a importantes transformaciones en todos los ámbitos como las estrategias subsistenciales -con la introducción de la agricultura y la ganadería-, la interacción del ser humano con su entorno, las relaciones sociales inter- e intragrupales, los sistemas simbólicos, la cultura material o las formas de ocupación del territorio, entre otros (Rojo et al., 2008b: 278 y ss.).

2. Todas las evidencias apuntan hacia la definición de contextos 'mesolíticos con elementos neolíticos', resultantes de la interacción entre grupos neolíticos de 'colonos pioneros' y comunidades locales de cazadoresrecolectores (García et al., 2011; Rojo et al., 2008), de los que Valmayor XI-II sería un claro exponente. Estos contactos, que habrían tenido lugar en un lapso cronológico aproximado entre el 5700-5600 y el 5300-5200 cal BC, dieron lugar posteriormente al surgimiento de comunidades neolíticas de $2 .^{\mathrm{a}}, 3 .^{\mathrm{a}}, 4 .^{\mathrm{a}} \ldots$ generación, que a su vez fomentaron nuevas relaciones intragrupales en

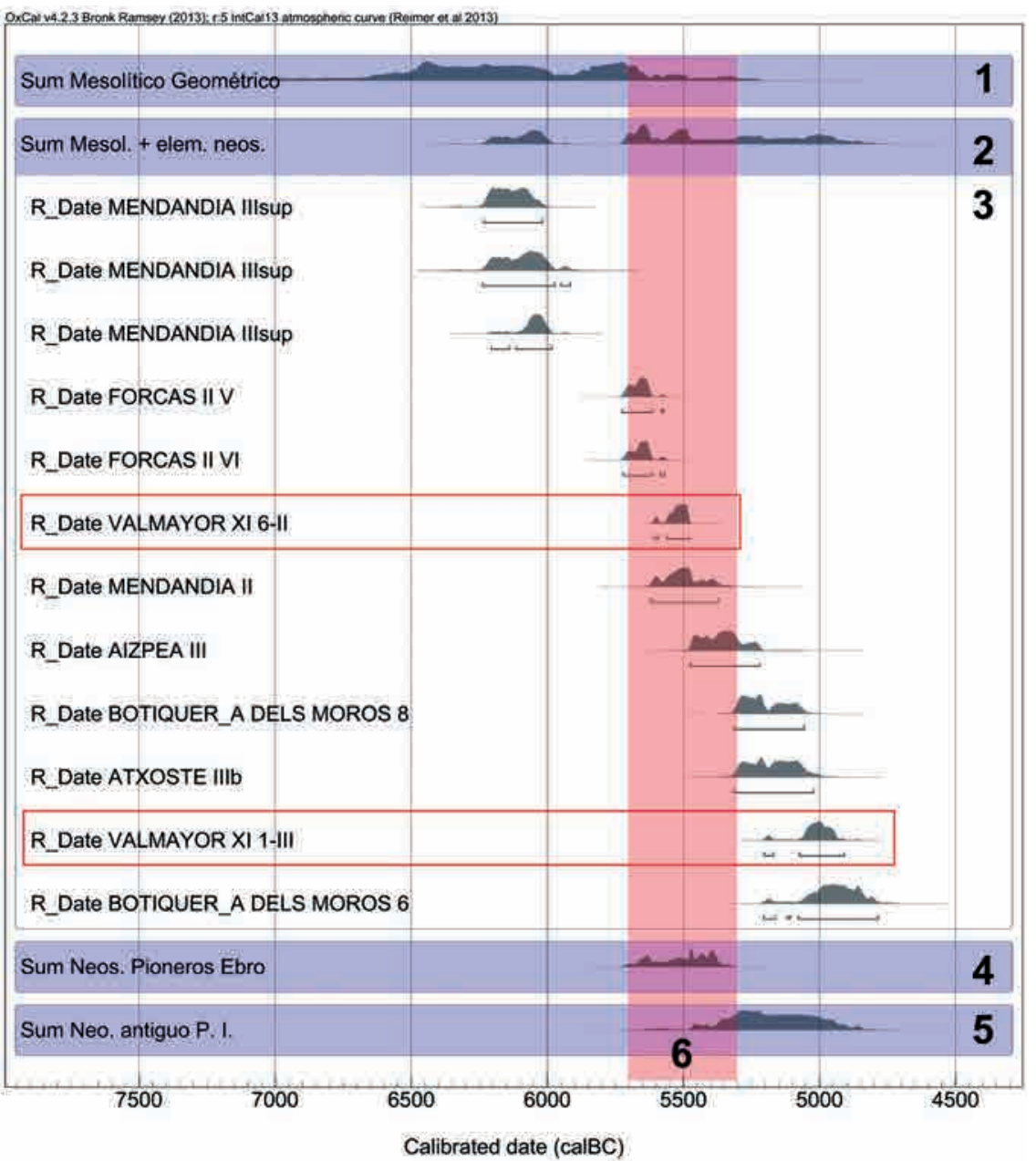

FIG. 15. Comparación de dataciones obtenidas en contextos del valle del Ebro, incluyendo las de Valmayor XI: 1) suma de dataciones de contextos del 'Mesolitico geométrico' (García, 2014); 2) suma de dataciones de contextos definidos como 'Mesolíticos con elementos neolíticos', incluidas las señaladas en este gráfico (ibídem); 3) serie de dataciones sobre muestras de vida corta de contextos similares a Valmayor XIII y III como Mendandia IIIsup y II (Alday, 2006; Alday et al., 2012), Forcas II (Utrilla et al., 2009), Aizpea III (Barandiarán y Cava, 2001), Botiquería dels Moros 8 (ibídem), Atxoste IIIb (Alday, 2012); 4) suma de dataciones de contextos definidos como 'Neolíticos pioneros' (García, 2014); 5) suma de dataciones propias de contextos del 'Neolítico antiguo' (ibídem); 6) periodo temporal de desarrollo de la neolitización.

el marco de diferentes escenarios espacio-temporales (ibidem).

3. Estas comunidades de $2 .^{\mathrm{a}}, 3 .^{\mathrm{a}}, 4 .^{\mathrm{a}} \ldots$ generación fueron las protagonistas de la fase de Valmayor XI-III y de otras múltiples y diversas ocupaciones 
-asentamientos al aire libre junto a buenas tierras de cultivo, campamentos especializados...- que proliferaron a lo largo de relativamente poco tiempo en gran parte del territorio peninsular.

La estratigrafía documentada en el Cingle de Valmayor XI constituye, por tanto, una completa secuencia de referencia para el estudio e interpretación de un periodo clave en el devenir de las sociedades prehistóricas.

\section{Bibliografía}

Alday, A. (1995): "Los elementos de adorno personal de la cueva del Moro de Olvena y sus derivaciones cronoculturales", Bolskan, 12, pp. 193-214.

Alday, A. (coord.) (2006): El legado arqueológico de Mendandia: Los modos de vida de los últimos cazadores en la Prehistoria de Treviño. Memorias Arqueología en Castilla y León, 15. Valladolid: JCyL.

Alday, A. (coord.) (2009): Reflejos del Neolitico ibérico: la cerámica boquique: caracteres, cronología y contexto. Arqueología y Patrimonio. Barcelona: EDAR.

Alday, A. (2012): "The Neolithic in the Iberian Peninsula: an explanation from the perspective of the participation of Mesolithic communities", Zephyrus, Lxix, pp. 75-94.

Alday, A.; Carretero, J. M.; Anderung, C. y GöthersTröм, A. (2012a): "Uros, genética, indígenas y colonos. A propósito de la neolitización de Europa”, Veleia, 29, pp. 335-358.

Alday, A.; Castaños, P. y Perales, U. (2012b): "Quand ils ne vivaient pas seulement de la chasse: preuves de domestication ancienne dans les gisements néolithiques d'Atxoste et de Mendandia (Pays Basque)", L'Anthropologie, 116, pp. 127-147. http://dx.doi.org/10.1016/j.anthro.2012.03.007

Alday, A.; Montes, L. y Baldellou, V. (2012c): “Cuenca del Ebro”. En Rojo, M.; Garrido, R. y García, I. (coords.): El Neolitico en la Península Ibérica y su contexto europeo. Madrid: Cátedra, pp. 291-331.

Alday, A. y Moral, S. (2011): "El dominio de la cerámica boquique: discusiones técnicas y cronoculturales”. En Bernabeu, J.; Rojo, M. y Molina, Ll. (coords.): Las primeras producciones cerámicas: el VI milenio cal AC en la Península Ibérica. Saguntum, Extra 12. Valencia, pp. 65-82.

Almeida, F.; Moreno-García, M. y Angelucci, D. E. (2009): "Under the Bulldozer's Claws: The EE15 Late Gravettian Occupation Surface from the Lagar Velho rock shelter", World Archaeology, 41 (2), pp. 242-261. http://dx.doi.org/10.1080/00438240902843790
Álvarez-Fernández, E. (2008): “The use of Columbella rustica (Class: Gastropoda) in the Iberian Peninsula and Europe during the Mesolithic and the early Neolithic". En Hernández Pérez, M.; Soler, J. A. y López PaDilla, J. A. (eds.): IV Congreso del Neolitico Peninsular (Alicante, 2006). Alicante: Diput. Prov. Alicante, t. II, pp. 103-111.

Aura J.; Carrión, M. Y.; Estrelles, E. y Jordà, G. (2005): "Plant economy of hunter-gatherer groups at the end of the last Ice Age: plant macroremains from the cave of Santa Maira (Alacant, Spain) ca. 120009000 вр", Vegetation History and Archaeobotany, 14 (4), pp. $542-550$. http://dx.doi.org/10.1007/s00334-005-0002-1

BADAL, E. (1998): "El interés económico del pino piñonero para los habitantes de la Cueva de Nerja”. En SANChidrián, J. L. y Simón, M. D. (eds.): Las culturas del Pleistoceno superior en Andalucía. Málaga: Patronato de la Cueva de Nerja, pp. 287-300.

Baldellou, V. (2011): "La cueva de Chaves (Bastarás-Casbas, Huesca)". En Bernabeu, J.; Rojo, M. y Molina, Ll. (coords.): Las primeras producciones cerámicas: el VI milenio cal AC en la Península Ibérica. Saguntum, Extra-12. Valencia, pp. 41-144.

Barandiarán, I. (1978): "El abrigo de la Botiquería dels Moros, Mazaleón (Teruel). Excavaciones arqueológicas de 1974", Cuadernos de Prehistoria y Arqueología Castellonense, 5, pp. 49-138.

BARANDIARÁn, I. y CAVA, A. (1989): La ocupación prehistórica del abrigo de Costalena (Maella, Zaragoza). Colección Arqueología y Paleontología, 6. Zaragoza: Diput. de Aragón.

Barandiarán, I. y Cava, A. (2000): "A propósito de unas fechas del Bajo Aragón: reflexiones sobre el Mesolítico y el Neolítico en la Cuenca del Ebro", SPAL, 9, pp. 293-326. http://dx.doi.org/10.12795/spal.2000.i9.16

Barandiarán, I. y CAVA, A. (coords.) (2001): Cazadoresrecolectores en el Pirineo navarro. El sitio de Aizpea entre 8000 y 6000 años antes de ahora. Veleia, Serie Mayor, 10. Vitoria: UPV.

Barrachina, C. (1996): "La industria òssia neolítica de la Cova Fosca (Ares de Maestrat, Castelló)", Cuadernos de Prehistoria y Arqueología Castellonense, 17, pp. 47-60.

Benavente, J. A. y Andrés, M. T. (1989): “El yacimiento neolítico de Alonso Norte (Alcañiz, Teruel). Memoria de las prospecciones y excavaciones arqueológicas de 1984-85", Al-Qannis, 1, pp. 2-56.

Benavente, J. A. y Andrés, M. T. (1992): "Informe sobre la excavación de Las Torrazas (Alcañiz, Teruel): Campaña de 1990", Arqueología Aragonesa, 1990, pp. 57-60.

Bernabeu, J.; Guitart, I. y Pascual Benito, L. L. (1989): "Reflexiones en torno al patrón de asentamiento en el País Valenciano entre el final del Neolítico y la Edad del Bronce", Saguntum, 22, pp. 99-124. 
Bernabeu, J. y Molina, L. (2009): La Cova de Cendres (Moraira-Teulada, Alicante). Alicante: Diput. Prov. de Alicante-MARQ.

BinforD, L. R. (1978): Nunamiut Ethnoarchaeology. New York: Academic Press.

Cava, A. (2000): "La industria lítica del Neolítico de Chaves (Huesca)", Salduie, 1, pp. 77-164.

Cava, A. (2006): "Las industrias líticas retocadas de Mendandia”. En Alday, A. (coord.): El legado arqueológico de Mendandia: Los modos de vida de los últimos cazadores en la Prehistoria de Treviño. Memorias Arqueología en Castilla y León, 15. Valladolid: JCyL, pp. 147-244.

Domingo, R. (2004): "La funcionalidad de los microlitos geométricos en yacimientos del Bajo Aragón: los casos de Botiquería dels Moros y Secans (Mazaleón, Teruel) y Costalena (Maella, Zaragoza)”, Salduie, 4, pp. 41-83.

Edo, M.; Antolín, F. y Barrio, M. ${ }^{a}$ J. (2012): "Can Sadurní (Begues, Baix Llobregat), de la captación de recursos abióticos al inicio de la minería de aluminofosfatos (10500-4000 cal ane) en el macizo de Garraf". En Borrell, M.; Borrell, F.; Bosch, J.; Clop, X. y Molist, M. (eds.): Actas del Congreso Internacional Xarxes al Neolitic (Gavá, 2011). Rubricatum, 5. Gavá: Institut Municipal de Gestió del Patrimoni Cultural i Natural, pp. 299-306.

García, I.; Garrido, R.; Rojo, M.; Alday, A.; García, J. y Sesma, J. (2011): “Cerámicas, estilo y neolitización: estudio comparativo de algunos ejemplos de la Meseta norte y Alto valle del Ebro". En Bernabeu, J.; Rojo, M. y Molina, L. L. (coords.): Las primeras producciones cerámicas: el VI milenio cal AC en la Península Ibérica. Saguntum, Extra-12. Valencia, pp. 83-103.

García, J. y Calvo, M. (2006): "Análisis de las evidencias macroscópicas de cocción en la cerámica prehistórica: una propuesta para su estudio", Mayurqa, 31, pp. 83-112.

García-Martínez de Lagrán, I. (2014): "La neolitización de la Meseta norte y de la alta y media cuenca del Ebro (España): premisas teóricas, análisis del registro y planteamiento de hipótesis", Zephyrus, LxxiII, pp. 83-107. http://dx.doi.org/10.14201/zephyrus20147383107

Gibaja, J. F. y Clop, X. (2012): "Cataluña”. En Rojo, M.; Garrido, R. y García, I. (coords.): El Neolitico en la Península Ibérica y su contexto europeo. Madrid: Cátedra, pp. 333-370.

Gibaja, J. F. y Palomo, A. (2004): "Geométricos usados como proyectiles. Implicaciones económicas, sociales e ideológicas en sociedades neolíticas del VI-IV milenio cal вс en el noreste de la Península Ibérica”, Trabajos de Prehistoria, 61 (1), pp. 81-97.

Gómez Lechumberri, F.; Rey, J. y Royo, J. I. (1992): "Estudio de materiales del poblado neolítico de Riols I (Mequinenza, Zaragoza). Campaña de 1990”. En Arqueología Aragonesa 1990. Zaragoza, pp. 47-53.
Hocketт, B. S. (1995): "Comparison of leporid bones in raptor pellets, raptor nests, and archaeological sites in the Great Basin", North American Archaeologist, 16 (3), pp. 223-238. http://dx.doi.org/10.2190/9UD3-TK6J-DJLB-8YXP

Ibáńez, J. J.; González Urquijo, J. E. y Moreno, M. (2002): "Le travail de la peau en milieu rural: le cas de la Jebala marocaine". En Audoin-Rouzeau, F. y Beyries, S. (eds.): XXIIe rencontres internationales d'archéologie et d'histoire d'Antibes Le travail du cuir de la Préhistoire à nos jours. Antibes: APDCA, pp. 79-97.

Jover, J. F. y García Atiénzar, G. (2014): “Sobre la neolitización de los grupos mesolíticos en el este de la Península Ibérica: la exclusión como posibilidad”, Pyrenae, 45 (1), pp. 55-88.

Juan Cabanilles, J. (1992): “La neolitización de la vertiente mediterránea peninsular: modelos y problemas". En Utrilla, P. (coord.): Aragón, litoral mediterráneo: intercambios durante la Prehistoria. Zaragoza: Institución Fernando el Católico, pp. 255-268.

Laplace, G. (1986): Tipología analitica. Vitoria: Upv.

Lloveras, L.; Moreno-García, M. y Nadal, J. (2008a): "Taphonomic analysis of leporid remains obtained from modern Iberian lynx (Lynx pardinus) scats", Journal of Archaeological Science, 35 (1), pp. 1-13. http://dx.doi.org/10.1016/j.jas.2007.02.005

Lloveras, L.; Moreno-García, M. y Nadal, J. (2008b): "Taphonomic study of leporid remains accumulated by the Spanish Imperial Eagle (Aquila adalberti)", Geobios, 41, pp. 91-100.

http://dx.doi.org/10.1016/j.geobios.2006.11.009

Lloveras, L.; Moreno-García, M. y Nadal, J. (2009): "The Eagle Owl (Bubo bubo) as a leporid remains accumulator: taphonomic analysis of modern rabbit remains recovered from nests of this predator", International Journal of Osteoarchaeology, 19, pp. 573- 592. http://dx.doi.org/10.1002/oa.995

Lyman, R. L. y Fox, G. L. (1989): "A critical evaluation of bone weathering as an indication of bone assemblage formation", Journal of Archaeological Science, 16, pp. 293-317. http://dx.doi.org/10.1016/0305-4403(89)90007-1

Maigrot, Y. (2010): "Étude comparative de deux séries d'en os impliqués dans la production céramique néolithique du Jura: Clairvaux XIV (Néolithique moyen) et Chalain 4 (Néolithique final)", Bulletin de la Société Préhistorique Française, 107 (4), pp. 737-753.

Martí, B. (2011): "La Cova de l'Or (Beniarrés, Alicante)". En Bernabeu, J.; Rojo, M. y Molina, Ll. (coords.): Las primeras producciones cerámicas: el VI milenio cal $A C$ en la Península Ibérica. Saguntum, Extra-12. Valencia, pp. 183-186.

Mason, S. (1992): Acorns in Human Subsistence. London: London University. 
Mazo, C. y Montes, L. (1992): "La transición Epipaleolítico-Neolítico Antiguo en el abrigo de El Pontet (Maella, Zaragoza)”. En Utrilla, P. (coord.): Aragón, litoral mediterráneo: intercambios durante la Prehistoria. Zaragoza: Institución Fernando el Católico, pp. 243-254.

McCorriston J. (1994): "Acorn eating and agricultural origins: California ethnographies as analogies for the ancient Near East”, Antiquity, 68, pp. 97-107.

Montes, L. (2014): "La Cultura material 2: las cerámicas". En Utrilla, P. y Mazo, C. (coords.): La Peña de las Forcas (Graus, Huesca). Un asentamiento estratégico en la confluencia del Ésera y el Isábena. Monografías Arqueológicas: Prehistoria, 46. Zaragoza, pp. 245-266.

Montes, L. y Alday, A. (2012): "Enredados en la malla neolítica de la cuenca del río Ebro. Redes, continuidades y cambios". En Borrell, M.; Borrell, F; Bosch, J.; Clop, X. y Molist, M. (eds.): Actas del Congreso Internacional Xarxes al Neolitic (Gavá 2-4 febrero 2011). Rubricatum, 5. Gavá, pp. 51-60.

OMs, X. (2008): "Caracterizació técnica, tipológica i cronológica de les ceràmiques del Neolític antic de la Cova Colomera (Prepirineu de Lleida)", Archivo de Prehistoria Levantina, 27, pp. 51-80.

Payne, S. (1987): "Reference codes for wear states in the mandibular teeth of sheep and goats", Journal of Archaeological Science, 14, pp. 609-614. http://dx.doi.org/10.1016/0305-4403(87)90079-3 http://dx.doi.org/10.1016/S0305-4403(87)80011-0

Ramón, N. (2006): La cerámica del Neolítico Antiguo en Aragón. Caesaraugusta, 77. Zaragoza: Institución Fernando el Católico.

Rivera, D. у Овón de Castro, C. (1991): La guía inCAFo de las plantas útiles y venenosas de la Peninsula Ibérica y Baleares (excluidas medicinales). Madrid: INCAFO.

Rojo, M.; Garrido, R. y García, I. (coords.) (2012): El Neolítico en la Península Ibérica y su contexto europeo. Madrid: Cátedra.

Rojo, M. A.; Kunst, M.; Garrido, R.; García, I. y MoRÁN, G. (2008): Paisajes de la Memoria: asentamientos del Neolitico antiguo en el Valle de Ambrona. Valladolid: Univ. Valladolid.

Rojo, M.; Peña, L.; Royo, J. I.; Tejedor, C.; GarcíaMartínez de Lagrán, I.; Arcusa, H.; Garrido, R.; Moreno, M.; Mazzuco, N.; Gibaja, J. F.; Ortega, D.; Bernd, K. y WAlt, K. (2013): "Pastores trashumantes del Neolítico antiguo en un entorno de alta montaña: secuencia crono-cultural de la Cova de Els Trocs, San Feliú de Veri (Huesca)", Boletín del Seminario de Arte y Arqueología, LXXIX, pp. 9-55.

Royo, J. I. (1984): "Excavaciones del Museo de Zaragoza en la necrópolis prehistórica del Barranco de la Mina Vallfera. Mequinenza, Zaragoza”, Boletín del Museo de Zaragoza, 3, pp. 5-24.
Royo, J. I. (1986-87): “El abrigo con grabados rupestres esquemáticos de Valmayor, Mequinenza (Zaragoza)”. En Actas I Congreso internacional de Arte Rupestre (Caspe, 1985). Bajo Aragón. Zaragoza, pp. 179-190.

Royo, J. I. (1987): “El poblado y necrópolis neolíticos del Barranco de la Mina Vallfera, Mequinenza (Zaragoza). Campaña de 1985”. En Arqueología Aragonesa 1985. Zaragoza, pp. 27-29.

Royo, J. I. y Gómez Lecumberri, F. (1991): “Prospecciones arqueológicas en el término municipal de Mequinenza (Zaragoza). Campaña de 1989”. En Arqueología Aragonesa 1988-1989. Zaragoza, pp. 31-34.

Royo, J. I. y Gómez Lecumberri, F. (1992): "Riols i: Un asentamiento neolítico al aire libre en la confluencia de los ríos Segre y Ebro". En Utrilla, M. P. (coord.): Aragón/Litoral Mediterráneo: Intercambios Culturales durante la Prehistoria. Zaragoza: Institución Fernando el Católico, pp. 297-308.

Royo, J. I. y Gómez Lecumberri, F. (1996): "Hábitat y territorio durante el Neolítico Antiguo y Medio/Final en la confluencia del Segre y el Ebro (Mequinenza, Zaragoza)". En Actas I Congrés del Neolitic a la Península Ibérica (Gavà-Bellaterra, 1995). Rubricatum, 1 (2). Gavá: pp. 767-780.

Royo, J. I. y Gómez Lecumberri, F. (1997): “Excavaciones y estudio de materiales en el poblado neolítico de Riols I durante 1992-1993”. En Arqueología Aragonesa 1993. Zaragoza, pp. 23-34.

Royo, J. I. y Gómez Lecumberri, F. (2004): “Prehistoria, Protohistoria y arte rupestre en la confluencia del Bajo Cinca con el Ebro”. En Montón, F. J. (coord.): Comarca del Bajo Cinca. Colección Territorio, 14. Zaragoza: Gob. Aragón, pp. 67-76.

Silver, I. A. (1969): "The ageing of domestic animals". En Brothwell, D. y Higss, E. S. (eds.): Science in Archaeology. London: Thames and Hudson, pp. 283-302.

Stiner, M. C.; Munro, N. D. y Surowell, T. A. (2000): "The tortoise and the hare: small-game use, the broadspectrum revolution, and Paleolithic demography", Current Anthropology, 41, pp. 39-73. http://dx.doi.org/10.1086/300102

Stiner, M. C.; Munro, N. D.; Surowell T. A. y Bar-JoSEF, O. (1999): "Paleolithic population growth pulses evidenced by small animal exploitation”, Science, 283, pp. 190-194. http://dx.doi.org/10.1126/science.283.5399.190

Tarrús, J. (2008): "La Draga (Banyoles, Catalonia), an Early Neolithic Lakeside Village in Mediterranean Europe", Catalan Historical Review, 1, pp. 17-33.

Utrilla, P. (2002): "Epipaleolíticos y neolíticos del Valle del Ebro". En Actas de las jornadas internacionales El paisaje en el Neolítico mediterráneo (Valencia, 2000). Saguntum, Extra-5. Valencia, pp. 179-208. 
Utrilla, P. y BeA, M. (2011): "Las cerámicas del Plano del Pulido (Caspe, Zaragoza)”. En Bernabeu, J.; Rojo, M. y Molina, Ll. (coords.): Las primeras producciones cerámicas: el VI milenio cal AC en la Península Ibérica. Saguntum, Extra-12. Valencia: pp. 147-149.

Utrilla, P. y Mazo, C. (1991): "Excavación de urgencia en el Abrigo de las Forcas (Graus-Huesca): las ocupaciones magdaleniense y epipaleolítica", Bolskan, 8, pp. $31-78$.
Utrilla, P.; Montes, L.; Mazo, C.; Martínez Bea, M. y Domingo, R. (2009): "El Mesolítico geométrico en Aragón”. En Utrilla, P. y Montes, L. (coords.): El Mesolitico geométrico en la Península Ibérica. Monografías arqueológicas, 44. Zaragoza, pp. 131-190.

ZAPATA, L. (2000): "La recolección de plantas silvestres en la subsistencia mesolítica y neolítica. Datos arqueobotánicos del País Vasco", Complutum, 11, pp. 157-169. 